\title{
Acquired Expression of Mutant Mitofusin 2 Causes Progressive Neurodegeneration and Abnormal Behavior
}

\author{
CKaori Ishikawa, ${ }^{1,2}$ Satoshi Yamamoto, ${ }^{3}$ (DSatoko Hattori, ${ }^{4}$ Naoya Nishimura, ${ }^{3}$ Haruna Tani, ${ }^{2}$ Takayuki Mito, ${ }^{1}$ \\ Hirokazu Matsumoto, ${ }^{3}$-Tsuyoshi Miyakawa, ${ }^{4}$ and Kazuto Nakada ${ }^{1,2}$ \\ ${ }^{1}$ Faculty of Life and Environmental Sciences, and ${ }^{2}$ Graduate School of Life and Environmental Sciences, University of Tsukuba, Tsukuba, Ibaraki, \\ 305-8572, Japan, ${ }^{3}$ Integrated Technology Research Laboratories, Pharmaceutical Research Division, Takeda Pharmaceutical Company, Ltd, Fujisawa, Kanagawa, \\ 251-8555, Japan, and ${ }^{4}$ Division of Systems Medical Science, Institute for Comprehensive Medical Science, Fujita Health University, Toyoake, Aichi, 470-1192, Japan
}

Neurons have high plasticity in developmental and juvenile stages that decreases in adulthood. Mitochondrial dynamics are highly important in neurons to maintain normal function. To compare dependency on mitochondrial dynamics in juvenile and adult stages, we generated a mouse model capable of selective timing of the expression of a mutant of the mitochondrial fusion factor Mitofusin 2(MFN2). Mutant expression in the juvenile stage had lethal effects. Contrastingly, abnormalities did not manifest until $150 \mathrm{~d}$ after mutant expression during adulthood. After this silent $150 \mathrm{~d}$ period, progressive neurodegeneration, abnormal behaviors, and learning and memory deficits similar to those seen in human neurodegenerative diseases were observed. This indicates that abnormal neuronal mitochondrial dynamics seriously affect survival during early life stages and can also significantly damage brain function after maturation. Our findings highlight the need to consider the timing of disease onset in mimicking human neurodegenerative diseases.

Key words: cognitive impairment; hyperactivity; MFN2; mitochondrial dynamics; progressive neurodegeneration

\section{Significance Statement}

To compare the dependency on mitochondrial dynamics in neurons in juvenile and adult stages, we generated a mouse model expressing a mutant of the mitochondrial fusion factor MFN2 in an arbitrary timing. Juvenile expression of the mutant showed acute and severe phenotypes and had lethal effects; however, post-adult expression induced delayed but progressive phenotypes resembling those found in human neurodegenerative diseases. Our results indicate that abnormal neuronal mitochondrial dynamics seriously affect survival during early life stages and can also significantly damage brain function after maturation. This strongly suggests that the timing of expression should be considered when establishing an animal model that closely resembles human neurodegenerative diseases.

\section{Introduction}

During the fetal period, there is a dramatic increase in the number of neurons; however, post-birth, the formation of complex

Received Aug. 20, 2018; revised Dec. 3, 2018; accepted Dec. 17, 2018.

Author contributions: K.I. wrote the first draft of the paper; K.I., S.Y., S.H., H.M., T. Miyakawa, and K.N. edited the paper; K.I., S.Y., and S.H. designed research; K.I., S.Y., N.N., and H.T. performed research; K.I., S.Y., and N.N. contributed unpublished reagents/analytic tools; K.I., S.H., and T. Mito analyzed data; K.I. wrote the paper.

This work was supported by Grants-in-Aid for Young Scientists B (16K18535 to K.I.), Scientific Research C (18K06203 to K.I.), Scientific Research B (16H04678 to K.N.), Challenging Exploratory Research (16K14719 to K.N.) from the Japan Society for the Promotion of Science (JSPS), AMED-CREST (18gm1110006 to K.N.) from the Japan Agency for Medical Research and Development (AMED), Life Sciences Fellowships from Takeda Science Foundation to K.I., Grant-in-Aid for Scientific Research on Innovative Areas (Platform of Advanced Animal Model Support (16H06276 to T. Miyakawa) from ministry of Education, culture, sports, science, and technology (MEXT) in Japan. Two professional English-speaking editors from Editage (http://www.editage.jp) have proofread and edited the paper. We thank all $\mathrm{Tg} / \mathrm{KO}$ group members of the Integrated Technology Research Laboratories, Pharmaceutical Research Division, Takeda Pharmaceutical Company, Ltd, for generating the CamK2a-tTA/TRE-hMFN2(D210V) mouse line; and the technical experts of the Division of System Medical Science, Institute for Comprehensive Medical Science, Fujita Health University, for their kind cooperation on our behavioral analyses. Behavioral analysis was networks and synapse elimination results in functional differentiation. Although functional differentiation is most prominent during the juvenile stage, neurons maintain plasticity after maturation. Thus, neurons possess different levels of plasticity during different developmental stages. Much remains unknown regarding the maintenance of neuronal plasticity and mechanisms underlying neuronal degeneration.

Mitochondria are dynamic organelles that behave as independent organisms and move intracellularly, with repeated fusion and fission events. "Mitochondrial dynamics", which refer to the

performed at Institute for Comprehensive Medical Science, Fujita Health University (Joint Usage/Research Center fo Genes, Brain and Behavior accredited by Minister of Education, Culture, Sports, Science and Technology) in Japan.

S.Y., N.N., and H.M. were full-time employees of Takeda Pharmaceutical Company, Ltd, at the time of this study. The remaining authors declare no competing financial intersts.

Correspondence should be addressed to Kaori Ishikawa at k_ishikawa@biol.tsukuba.ac.jp or Kazuto Nakada at knakada@biol.tsukuba.ac.jp.

https://doi.org/10.1523/JNEUROSCI.2139-18.2018

Copyright $\odot 2019$ the authors $\quad 0270-6474 / 19 / 391588-17 \$ 15.00 / 0$ 
morphology and intracellular distribution of mitochondria, are important for the maintenance of normal mitochondrial respiratory function and cellular ATP supply (Chen et al., 2003; Ishihara et al., 2009). Neurons require enormous amounts of ATP, necessitating normal mitochondrial dynamics (Khacho and Slack, 2018). In fact, a mutation in the mitochondrial fusion factor Mitofusin 2 (MFN2) causes Charcot-Marie-Tooth disease type 2A (CMT2A), a hereditary neuropathy that primarily presents with muscle atrophy and sensory disturbance (Zuchner et al., 2004; Feely et al., 2011; Stuppia et al., 2015). Several transgenic and knock-in mice with $M f n 2$ mutations have been established as CMT2A models (Detmer et al., 2008; Cartoni et al., 2010; Strickland et al., 2014; Bannerman et al., 2016). Although these models differ in the quality and degree of the disease state, all mice exhibit neuropathy-like symptoms, demonstrating the importance of $M f n 2$ in maintaining normal neuronal function (Detmer et al., 2008; Cartoni et al., 2010; Strickland et al., 2014; Bannerman et al., 2016). In these mice, mutant genes are expressed from the fetal phase; thus, gene expression during developmental and growth phases cannot be distinguished from expression after maturation, which is a common feature of mouse models of neurodegenerative diseases (Figiel et al., 2012; Lee et al., 2012; Sasaguri et al., 2017). In most human neurodegenerative diseases, the completed neural network is subject to gradual damage after adulthood, resulting in a loss of neurons. The mechanisms underlying neurodegeneration are unknown. To elucidate these, it is necessary to evaluate neural damage separately during the juvenile growth phase and after adulthood. To perform these evaluations, an experimental model that enables the loading of stress-induced neural damage at selective time points and observation of the effects of this stress within a relatively short period is required.

Abnormal mitochondrial dynamics are implicated in CMT2A and other neurodegenerative diseases. Further, experimentally manipulating the expression of regulatory genes for mitochondrial dynamics enables the fast induction of an abnormal state, allowing rapid investigation of the effects of respective gene expression. We generated a novel mouse strain that introduces a pathogenic mutant of MFN2 [hMFN2(D210V)] specifically in neurons and allows temporal control of gene expression. This MFN2 mutant has previously been reported clinically in a family with optic nerve atrophy and hereditary neuropathy, and causes abnormalities in mitochondrial morphology and reduces cellular respiration (Rouzier et al., 2012); therefore, we hypothesized that hMFN2(D210V) expression may be a suitable cause of stress to evaluate abnormal mitochondrial dynamics in neurons.

Using this newly generated mouse line, we showed that expression of mutant MFN2 at different time points in development resulted in different pathology. When the mutant MFN2 was expressed from birth, more than half of the mice died by 10 weeks of age. When the same mutant was expressed after maturation, almost no abnormalities were detected for $>150 \mathrm{~d}$, followed by sluggish weight gain and significant abnormalities in behavior, learning, and memory 250-300 d after expression. These results suggested that Mfn2-induced mitochondrial fusion is ubiquitously important for the maintenance of neural function throughout life and simultaneously plays a critical role in the maintenance and growth of healthy individuals during the juvenile stage.

\section{Materials and Methods}

Camk2a-tTA/TRE-hMFN2(D210V) Tg mice. A human MFN2 cDNA was cloned to the pCR4 Blunt TOPO vector (ThermoFisher Scientific). The D210V mutation was introduced into hMFN2 cDNA using a QuikChange Site-Directed Mutagenesis Kit according to the manufac- turer's instructions (Agilent Technologies). The hMFN2(D210V) cDNA was inserted into a pTRE-Tight vector (Clontech Laboratories). The expression unit was excised at the Xho I site and microinjected into the pronucleus of oocytes from C57BL/6J mice (CLEA Japan; Fig. 1A). Integration of the transgene into the mouse genome was confirmed by genomic PCR with primers (Table 1), which amplify a transgene-specific sequence (Fig. $1 B$ ). Thirty-four $\mathrm{F}_{0}$ founder mice were crossed with Camk2a-tTA Tg mice (RRID:IMSR_JAX:007004, Stock \#007004, The Jackson Laboratory; Mayford et al., 1996), and from the resultant double-Tg mouse lines, one line was selected based on the expression levels of the transgene. Other lines also showed the tendency for brain atrophy, confirming the pathogenicity of hMFN2(D210V) in mice. Expression of the transgene was controlled by feeding and removing a doxycycline (Dox)-containing pellet (5TP7, Japan SLC). We confirmed that long-term administration of Dox had no significant effects on the results of this study using an independent cohort of mice. All animal experiments were approved by the Institutional Animal Care and Use Committee of the University of Tsukuba, the Takeda Experimental Animal Care and Use Committee, and the Institutional Animal Care and Use Committee of Fujita Health University.

Experimental design. We evaluated the effects of expressed hMFN2 $(\mathrm{D} 210 \mathrm{~V})$ in two different time courses using our inducible animal model. One was juvenile expression; the transgene was expressed from just after birth continuously (Fig. $1 C$, top, $D$ ), and the other was adult expression; the expression of transgene started at 8 weeks of age (Fig. $1 C$, bottom, $E$ ). We used only male animals in all experiments because of the number of evaluated factors in behavior or learning tests that are sensitive to hormonal changes in female mice.

Evaluation of the transgene expression patterns. To evaluate the timing and distribution of transgene expression, we performed in situ hybridization against the $t T A$ transgene. First, an $817 \mathrm{bp}$ fragment of the $t T A-$ containing region was amplified from genome DNA extracted from a Tg mouse. DNA templates for in vitro transcription were generated from the product using T7 promoter-combined primer sets. All primer sequences are listed in Table 1. Both antisense and sense riboprobes were transcribed using Digoxigenin (DIG)-labeled UTP (Roche), and purified by ProbeQuant G-50 Micro Columns (GE Healthcare). Embryos and brain samples were fixed in $4 \%$ paraformaldehyde and $10 \mu \mathrm{m}$ of cryosections were prepared. Hybridization was performed using hybridization buffer [ $5 \times$ SSC, $50 \%$ formamide, $5 \times$ Denhardt's solution, yeast tRNA (250 $\mu \mathrm{g} / \mathrm{ml})$, salmon sperm DNA (500 $\mu \mathrm{g} / \mathrm{ml})$, and denatured DIG-labeled riboprobe $(500 \mathrm{ng} / \mathrm{ml})]$, overnight at $72^{\circ} \mathrm{C}$. After washing with $2 \times \mathrm{SSC}$, sections were blocked with blocking buffer [ $0.1 \mathrm{~m}$ Tris-HCl, $\mathrm{pH} 7.5$, with $1 \%$ blocking reagents (Roche), $10 \mathrm{~mm}$ maleic acid, and $0.15 \mathrm{M} \mathrm{NaCl}$ ] for $1 \mathrm{~h}$, then reacted with anti-DIG-AP (Roche) overnight at $4^{\circ} \mathrm{C}$. After equilibration with reaction buffer [0.1 M Tris- $\mathrm{HCl}, \mathrm{pH} 9.5$, with $0.1 \mathrm{M}$ $\mathrm{NaCl}$ and $10 \mathrm{mM} \mathrm{MgCl}_{2}$ ], the chromogenic reaction was performed using NBT/BCIP-containing buffer [1/50 NBT/BCIP stock solution (Roche) in reaction buffer]. The reaction was stopped with $10 \mathrm{~mm}$ EDTA-containing PBS. Following short counterstaining with nuclear fast red (SigmaAldrich), sections were dehydrated and cleared, then mounted with Malinol (Muto Pure Chemicals).

Quantification of mRNA expression levels. Total RNA was extracted from the cortex using the RNeasy Mini Kit (QIAGEN). Reverse transcription was performed using a High-Capacity cDNA Reverse Transcription Kit (ThermoFisher Scientific). Quantification of the mRNA levels of hMFN2 (transgene), mMfn2 (endogenous), and $\beta$-actin were performed by real-time PCR using the ABI 7900HT (Applied Biosystems). All primer and probe sequences are listed in Table 1.

Quantification of protein expression levels. Total protein was extracted from the cortex using an EzRIPA Lysis kit (ATTO). SDS-PAGE was performed using NuPAGE 4-12\% Bis-Tris gel (ThermoFisher Scientific) and MOPS Running Buffer (ThermoFisher Scientific), and proteins were transferred to PVDF membrane. After blocking with a PVDF Blocking Reagent (TOYOBO), membranes were incubated with the following antibodies: anti-Mfn1 (RRID:AB_581724; H00055669-M04, Abnova), anti-Mfn2 (RRID:AB_530127; H00009927-M03, Abnova), anti-pS616 Drp1 (RRID:AB_2085352; 3455, Cell Signaling Technology), anti-Drp1 (RRID:AB_10950498; 8570, Cell Signaling Technology), anti-Mff (RRID:AB_2142463; 17090-1-AP, Proteintech), anti-COX IV (RRID: 

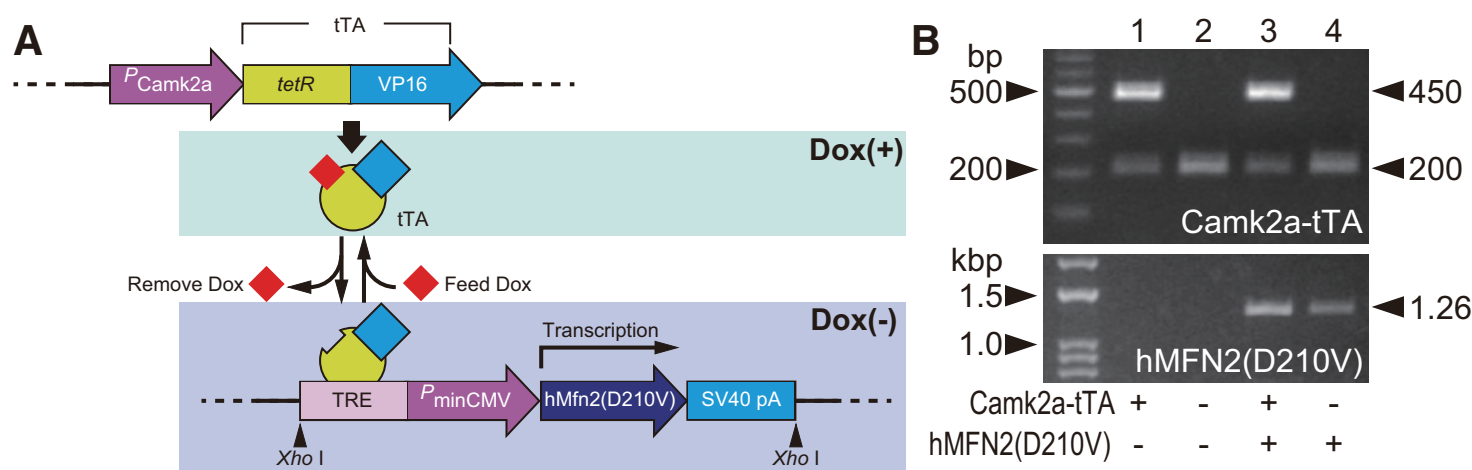

C
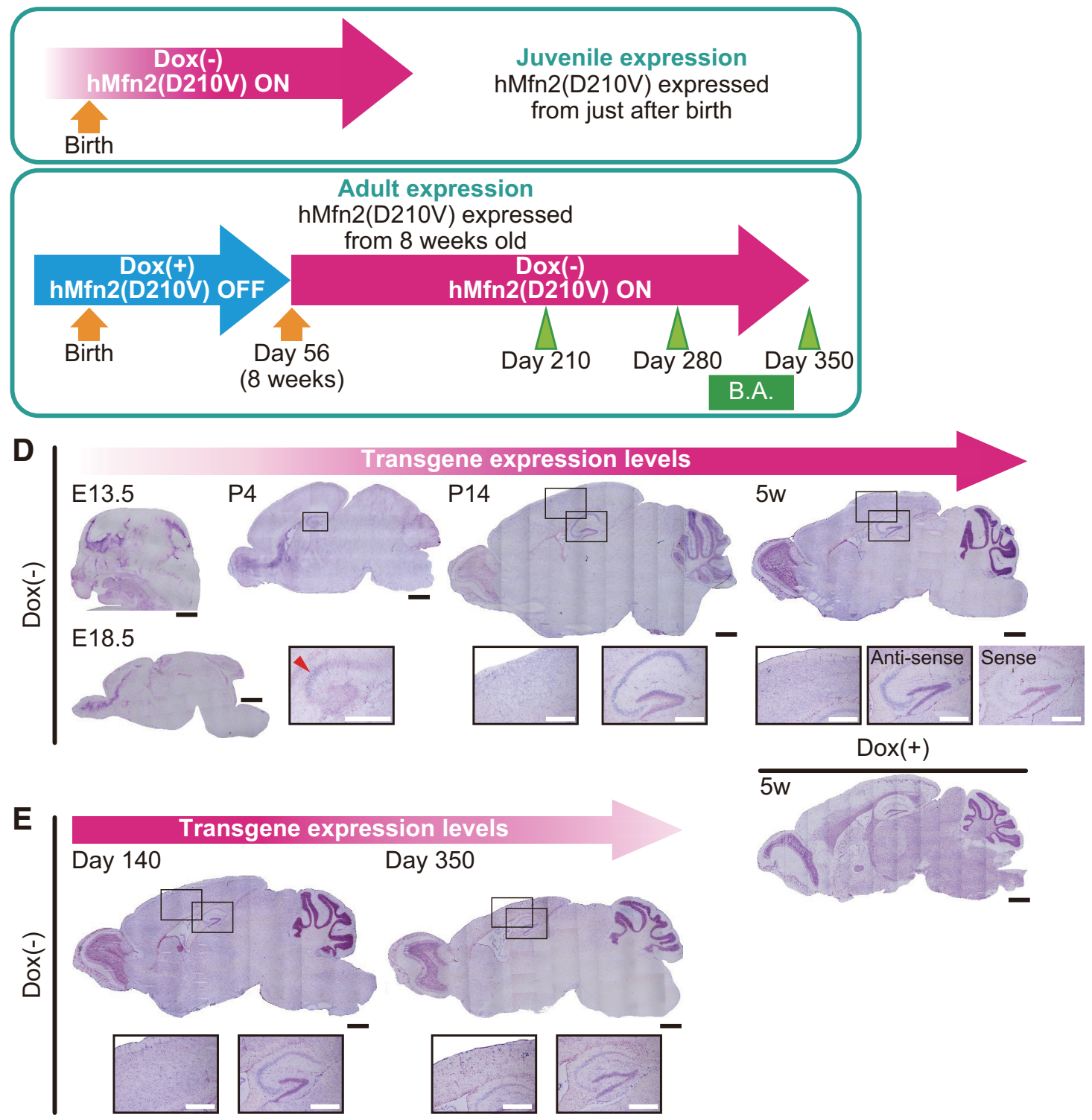

Figure 1. Schematic illustration of the experimental design. $A$, Schematic illustration of the construct used for the generation of the Camk2a-tTA/TRE-hMfn2(D210V) mouse line. Because expression of hMFN2(D210V) can be induced by a Tet-off system, switching on/off can be controlled with Dox-containing pellets. B, A representative image of genotyping of the mouse line by genome PCR. Integration and absence of Camk2a-tTA transgene resulted in the amplification of 450 and 200 bp fragments, respectively. Camk2a-tTA mice were maintained by mating of hemizygote with noncarrier; therefore, all Camk2a-tTA ${ }^{+}$mice are hemizygote (lanes 1 and 3). The integration and absence of the hMFN2 transgene resulted in 1256 bp amplicon and without amplicon, respectively. C, Schematic illustration of the time courses of Dox treatment to regulate expression of hMFN2(D210V). Top and bottom indicate "juvenile expression" and "adult expression", respectively. Green arrowheads and green band with "B.A." indicate the time points when physiological and biochemical analyses were performed and the period which behavior analyses were performed, respectively. $\boldsymbol{D}, \boldsymbol{E}$, Representative sagittal images of in situ hybridization to visualize expression levels of $t T A$, the transgene, from embryonic stages to early postnatal days of juvenile expression group (D) and after adulthood in the adult expression group (E). Transgene-positive areas are shown in blue, and nuclei-abundant areas are shown in red or purple. Note the transgene expression was almost absent before birth (E13.5 and E18.5) but induced after birth, especially in the hippocampus and cortex $(\mathrm{P} 4<\mathrm{P} 14<5 \mathrm{w} ; \boldsymbol{D})$. In contrast, transgene expression decreased at Day 350 compared with Day 140 in the adult expression group (E). The specificity of the antisense riboprobe was confirmed by the negative results from the sense riboprobe against serial section and the $\operatorname{Dox}(+)$ mouse $(\boldsymbol{D}$, "Sense" and "Dox $(+)$ "). Scale bars: black, $1 \mathrm{~mm}$; white, $500 \mu \mathrm{m}$. 
Table 1. A list of primers and probes used in this research

\begin{tabular}{|c|c|c|c|}
\hline \multirow[b]{2}{*}{ Application } & \multirow[b]{2}{*}{ Sequence } & \multicolumn{2}{|l|}{ Label } \\
\hline & & $5^{\prime}$ End & $3^{\prime}$ End \\
\hline \multicolumn{4}{|c|}{ Camk2a-tTA transgene } \\
\hline Forward & CGCTGTGGGGCATTTTACTTTAG & & \\
\hline Reverse & CATGTCCAGATCGAAATCGTC & & \\
\hline \multicolumn{4}{|c|}{ Internal positive control for } \\
\hline Forward & СAAATGTTGCTTGTCTGGTG & & \\
\hline Reverse & GTCAGTCGAGTGCACAGTTT & & \\
\hline \multicolumn{4}{|c|}{ hMFN2 CDNA transgene genotyping } \\
\hline Forward & ACTCATCATGGACTCCCTGCACATG & & \\
\hline Reverse & GCATTCATTTTATGTTTCAGGTTCAG & & \\
\hline \multicolumn{4}{|c|}{ Amplification of $t T A$ region } \\
\hline Forward & GCCTTAGCCATTGAGATGTTA & & \\
\hline Reverse & CGGTAAACATCTGCTCAAACT & & \\
\hline \multicolumn{4}{|c|}{ Generation of $t T A$ anti-sense riboprobe } \\
\hline Forward & $\begin{array}{l}\text { TAATACGACTCACTATAGGGGCCTTAGCCATTGAGA } \\
\text { TGTTAGCCATTGAGATGTTA }\end{array}$ & & \\
\hline Reverse & CGGTAAACATCTGCTCAAACT & & \\
\hline \multicolumn{4}{|c|}{ Generation of $t T A$ sense riboprobe } \\
\hline Forward & GCCTTAGCCATTGAGATGTTA & & \\
\hline Reverse & $\begin{array}{l}\text { TAATACGACTCACTATAGGGGGTAAACATCTGCTC } \\
\text { AAACTACATCTGCTCAAACT }\end{array}$ & & \\
\hline \multicolumn{4}{|c|}{ Quantification of $h M F N 2 \mathrm{mRNA}$} \\
\hline Forward & CGGCAGCCTAGTGAGTGTGA & & \\
\hline Reverse & AAAACGAGGTCATCCTTCAGAAGT & & \\
\hline Probe & СCCAACTCTAAGTGCC & FAM & MGB \\
\hline \multicolumn{4}{|c|}{$\begin{array}{l}\text { Quantification of internal } \\
\text { mMFN2 mRNA }\end{array}$} \\
\hline Forward & AGATTACGGAGGAAGTGGAAAGG & & \\
\hline Reverse & GAGGCGCCTGATCTCTTCAG & & \\
\hline Probe & AGGTGTCCACAGCCAT & FAM & MGB \\
\hline \multicolumn{4}{|c|}{ Long-range PCR of mtDNA } \\
\hline Forward & GGTTGGTTTGTTCAACGATTAAAGTCCTACGTG & & \\
\hline Reverse & GAGGTGATGTTTTTGGTAAACAGGGGGGGT & & \\
\hline
\end{tabular}

AB_2085424; 4850, Cell Signaling Technology), anti-Tom20 (RRID: AB_2207533; sc11415, Santa Cruz Biotechnology), and anti- $\alpha$-Tubulin (RRID:AB_477579; T-5168, Sigma-Aldrich). The secondary antibodies, HRP-linked anti-mouse IgG (RRID:AB_330924; 7076, Cell Signaling Technology) or anti-rabbit IgG (RRID:AB_2099233; 7074, Cell Signaling Technology), were used and reacted with ECL substrate (ThermoFisher Scientific). Detection and quantification were performed using ImageQuant LAS 4000 mini (GE Healthcare) and MultiGauge software (FUJIFILM).

Physiological analyses. A small blood sample was collected by venipuncture of the tail vein. To measure blood glucose and blood lactate levels, a Breeze 2 Blood Glucose Monitoring System (Bayer) and Lactate Pro 2 (ARKRAY) were used, respectively.

Biochemical analyses. The mitochondrial fraction was prepared from homogenized cortex lysate and used for measurement of mitochondrial respiratory complex activities. To measure complex I + III, II + III, and IV activities, NADH and oxidized cytochrome $c$, sodium succinate and oxidized cytochrome $c$, and reduced cytochrome $c$ were added as substrates, respectively. Reduction (I + III, II + III) and oxidation (IV) of cytochrome $c$ were detected as transition of absorption at $550 \mathrm{~nm}$. Mean reaction speeds were compared between $\operatorname{Dox}(+)$ and $\operatorname{Dox}(-)$ groups, and reported as relative values $[\operatorname{Dox}(+)$ group was considered $100 \%]$.

Histological analyses. Brain or muscle tissue was extracted immediately after euthanasia, and using brain matrices, the brain hemisphere was cut into a $5 \mathrm{~mm}$ cube that included bregma $-1.70 \mathrm{~mm}$. Tissue was fixed with $10 \%$ formalin in PBS overnight. After dehydration, tissue was paraffinembedded and sliced into $6 \mu \mathrm{m}$ sections. For histopathological evaluation, sections were stained with hematoxylin and eosin after being deparaffinized, and then sealed with Malinol (Muto Pure Chemicals) after dehydration and clearing. For immunohistochemical analysis, paraffin sections were incubated with anti-1-methyladenosine (m1A) primary antibody (RRID:AB_2728758; D345-3, MBL) overnight, and visualized by the EnVision + Single Reagents (HRP Mouse; Dako). To detect amyloid plaques, sections were stained with Congo red solution for $10 \mathrm{~min}$ after a hematoxylin counter stain, then sections were alkalin- ized with $0.1 \mathrm{M} \mathrm{KOH}$ solution and sealed after dehydration and clearing. Preparations were observed using a light microscope Leica DMRE under transmitted and/or polarized light. Images were obtained using digital color camera DFC310 FX (Leica) and processed by a microscope software platform Leica Application Suite (LAS v4.5). For electron microscope analysis, extracted brain tissue was fixed with $2 \%$ paraformaldehyde and $2 \%$ glutaraldehyde in $0.1 \mathrm{M}$ cacodylate buffer at $4^{\circ} \mathrm{C}$ overnight, followed by postfixation with $2 \%$ osmium tetroxide for $3 \mathrm{~h}$. Dehydrated samples were infiltrated with propylene oxide $(\mathrm{PO})$ and were put into a 7:3 mixture of $\mathrm{PO}$ and resin (Nisshin EM) for $1 \mathrm{~h}$, then PO was volatilized. Samples were transferred into a fresh $100 \%$ resin, polymerized, and ultrathin sectioned at $70 \mathrm{~nm}$ with a diamond knife using an ultra-microtome (Leica). The sections were mounted on copper grids and stained with $2 \%$ uranyl acetate for $15 \mathrm{~min}$, followed by a secondary stain with a Lead stain solution (Sigma-Aldrich) for $3 \mathrm{~min}$. Stained sections were observed by transmission electron microscopy (TEM; JEOL).

Long-range PCR. Total DNA was extracted from the brain cortex using a Gentra Puregene Tissue Kit (QIAGEN), and 100 ng of DNA was prepared as a template. PCR was performed using the Expand Long Template PCR System (Roche) according to the manufacturer's protocol. The primer sequences used for this PCR are listed in Table 1. Products were electrophoresed using $0.8 \%$ STAR Agar (RIKAKEN).

Characterization of mice. All evaluations described below were performed during Days 300-340 (Fig. 1C) using male mice.

Neurological screen and neuromuscular strength test. A grip strength meter (O'HARA) was used to assess forelimb grip strength. Mice were lifted by holding the tail so that their forepaws could grasp a wire grid. The mice were then gently pulled backward by the tail with their posture parallel to the surface of the table until they released from the grid. The peak force applied by the forelimbs of the mouse was recorded in Newtons $(\mathrm{N})$. Each mouse was tested three times, and the greatest measured value was used for data analysis. In the wire hang test, mice were placed on a wire mesh that was then slowly inverted, such that they gripped the wire to not fall off. Latency to fall was recorded, with a 60 s cutoff time. Limb reflexes during tail hanging were also observed.

Evaluation of motor coordination: balance beam test. Motor coordination and balance were tested with the balance beam test. Motor coordination was quantitatively assessed using trial performance, moving speed, and number of slips along a rod $1 \mathrm{~m}$ in length (diameter, $28 \mathrm{~mm}$ ). After six trials, six additional trials with a narrow rod (diameter, $11 \mathrm{~mm}$ ) were conducted. The increment in the moving speed and decrements in the number of slips were quantified as indices of motor learning using Image BT software (see Image analysis).

Evaluation of behavior: home cage and open-field tests. Home cage activity was monitored by a system that automatically analyzes the locomotor activity of mice in their home cage (Miyakawa et al., 2003). The system contains a home cage $(29 \times 18 \times 12 \mathrm{~cm})$ and a filtered cage top, separated by a metal stand (height, $13 \mathrm{~cm}$ ) with an infrared video camera attached to the top. Mice were individually housed and their locomotor activity was monitored for $7 \mathrm{~d}$. Data from each cage were analyzed at a rate of 1 frame per second, and distance traveled was measured automatically using Image HA software (see Image analysis). The open-field test was performed using an open-field apparatus $(40 \times 40 \times 30 \mathrm{~cm}$; Accuscan Instruments). The total distance traveled, vertical activity, and time spent in the center area were recorded.

Evaluation of learning and memory: Barnes maze and T-maze. The Barnes circular maze task (Barnes, 1979), was conducted on a white circular surface ( $1.0 \mathrm{~m}$ in diameter, with 12 holes equally spaced around the perimeter; O'HARA). The circular open field was elevated $75 \mathrm{~cm}$ off the floor. A black Plexiglas escape box $(17 \times 13 \times 7 \mathrm{~cm})$ was located under one of the holes. The hole above the escape box represented the target, analogous to the hidden platform in the Morris water maze task. The number of errors and latency to reach the target were automatically calculated by ImageBM software (see Image analysis). The spontaneous alternation test was conducted using an automated T-maze apparatus (O'HARA). The correct response was choosing the other arm that had not been chosen on the first trial. The location of the sample arm (left or right) was varied pseudorandomly across trials using the Gellermann schedule so that mice received equal numbers of left and right presenta- 
tions. Data acquisition, control of sliding doors, and data analysis were performed by ImageTM software (see Image analysis).

Image analysis. The software used for the behavioral experiments (ImageBT, HA, BM, and TM) were based on the ImageJ program (http://rsb. info.nih.gov/ij/), which were modified for each test by Tsuyoshi Miyakawa (available through O'HARA).

Statistical analysis. The sample size of each test and statistical method used in each figure are stated in the figure legends. Statistical analysis for all data, except behavior, was conducted using GraphPad Prism 6.0, whereas Stat View (SAS Institute) was used for behavioral analysis. Detailed statistical parameters for all data presented in this paper are shown in Fig. 2-1, available at https://doi.org/10.1523/JNEUROSCI.2139-18. 2018.f2-1.

\section{Results}

\section{Generation of the hMFN2(D210V)-expressing mouse model}

Mice expressing tTA downstream of the neuron-specific Camk2a promoter and mice with the hMFN2(D210V) sequence inserted downstream of TRE (Tet response element) were mated to produce mice expressing hMFN2(D210V) in the absence of Dox (Fig. 1A). Whereas changes in endogenous $m M f n 2$ expression were minimal from the juvenile to old stages in both $\operatorname{Dox}(+)$ and $\operatorname{Dox}(-)$ groups, the expression of hMFN2 was detected only in the $\operatorname{Dox}(-)$ group. Furthermore, its expression was $\sim$ twofold to fourfold higher than endogenous $\mathrm{m} M f n 2$ expression (Fig. 2A, B). Together, this demonstrates the generation of a mouse model with temporal control, induced by absence of Dox administration, of hMFN2(D210V) expression.

We found that the amount of MFN2 protein, the transgene product, was increased in the $\operatorname{Dox}(-)$ group, whereas no changes in Mfn1 expression, also involved in mitochondrial fusion, were observed. There was a reduction in the amount of pS616-Drp1, the active form of Drp1 responsible for mitochondrial division. Mff, an adaptor protein for Drp1, was also slightly reduced. There were no differences in the amount of the mitochondrial outer membrane protein Tom20; however, in the $\operatorname{Dox}(-)$ group, there was a reduction in COX IV, a subunit of the respiratory chain complex (Fig. 2C,D).

\section{Juvenile expression of hMFN2(D210V) has lethal effects}

In humans, the hMFN2(D210V) mutation causes neuropathies and abnormalities in mitochondrial morphology (Rouzier et al., 2012); however, its effect in mice was unknown. Consequently, we investigated the effect of continuous mutant expression from just after birth (Fig. $1 C, D$ ). The results of which proved to be severe; weight loss was observed from at least 4 weeks of age and more than half of the mice died between 9 and 10 weeks of age (Fig. $3 A, B$ ). Brain comparisons at 10 weeks of age identified major cerebral cortex atrophy (Fig. $3 C$ ), where there was high transgene expression (Fig. 1D). Further, there was a significant reduction in whole-brain weight and mitochondrial respiration activities (Fig. $3 D, E$ ). Additionally, there was an aggregation of uniformly fragmented mitochondria in clusters around the nucleus in hippocampal neurons. Many cases of irregular mitochondria, including those with abnormal inner membrane structures and those which were swollen with absent inner membranes, were observed among the aggregated mitochondria (Fig. $3 F$ ). Although not all functions of MFN2 [such as tethering mitochondria and endoplasmic reticulum (de Brito and Scorrano, 2008), and regulating meiosis (Liu et al., 2016)] were evaluated, we found that the expression of hMFN2(D210V) seemed to suppress normal Mfn2 functioning associated with mitochondrial fusion. Therefore, juvenile expression of hMFN2(D210V) had a serious and immediate effect on the morphology, distribution, and function of mitochondria in neurons, and induced acute neurodegeneration. This acute progression was the most likely mechanism for the debilitation associated with a disturbance in homeostasis controlled by brain, which was fatal.

\section{Adult expression of hMFN2(D210V) does not result in immediate physiological manifestations}

Next, we observed the effect of hMFN2(D210V) expression from 8 weeks of age (Day 56), at which point brain maturation is almost complete; these mice will hereby be referred to as "adult expression" mice (Fig. 1C,E). Compared with juvenile expression, there were almost no deaths within 1 year in the adult expression group (Fig. $4 A$ ). Additionally, no noticeable abnormalities were observed in body weight, blood glucose, and lactate levels, mitochondrial respiratory activities, and brain weight until $\sim$ Day 200 (Fig. 4B-H). However, thereafter, weight gain in the mutant-expressing group became sluggish and there was a tendency for reduced body weight from $\sim$ Day 300 (Fig. 4B). Similarly, blood glucose levels, mitochondrial respiratory chain complex activity, and brain weight were all significantly reduced at Day 280, and this effect increased up to Day 350 (Fig. 4C,E-H). Conversely, there was a significant increase in blood lactate level at Day 280, which was absent at Day 350 (Fig. 4D). These results show that, in contrast with expression in juvenile mice, the manifestation of hMFN2(D210V) expression at the adult stage manifested $>150 \mathrm{~d}$ post-expression.

\section{Adult expression of hMFN2(D210V) induces progressive neurodegeneration}

Mice were dissected at Day 350 and atrophy of the cerebral cortex was observed (Fig. 5A). Hematoxylin-eosin stained paraffin sections revealed extensive atrophy of the hippocampus in the adult expressing group, with poor delineation of the cell layers, a reduction in cerebral cortex thickness by $\sim 50 \%$, and expansion of the lateral ventricles (Fig. 5B). When the same region was stained with an antibody against m1A (Mishima et al., 2014), a modified tRNA that is an indicator of tissue oxidative damage, we found that the amount of $\mathrm{m} 1 \mathrm{~A}$ in remaining brain tissue was intensified in the mutant-expressing group. This indicated an accumulation of oxidative damage (Fig. $5 B$ ). Electron microscopy of the hippocampal region identified two types of regions; regions with perinuclear aggregation of fragmented mitochondria in live neurons, and regions with gaps resulting from a lack of neurons because of progressed neurodegeneration (Fig. 5C). We hypothesized that the former region would gradually transit to the state of the latter region. Among the aggregated mitochondria, there were mitochondria with abnormal membrane structures or completely disintegrated membranes (Fig. 5C). These findings, including atrophy of the cortex, were similar to those observed at 10 weeks of age in juvenile expression group (Figs. $3 F, 5 C$ ). The change in brain weight following mutant expression (Fig. 4H) is thought to be because of the progressive induction of neurodegeneration. To elucidate the mechanism associated with hMFN2(D210V) expression leading to neurodegeneration, we also visualized mitochondrial morphology and distribution in neurons before neurodegeneration. On Day $140 \quad(\sim 100 \mathrm{~d}$ after hMFN2(D210V) expression was induced), the mitochondria had gathered and created some clusters in neurons; however, these clusters were not tight compared with observations on Day 350. Furthermore, the mitochondrial morphology and inner membrane structures were normal (Fig. 5D). Because mitochondrial dysfunction and physiological abnormalities 

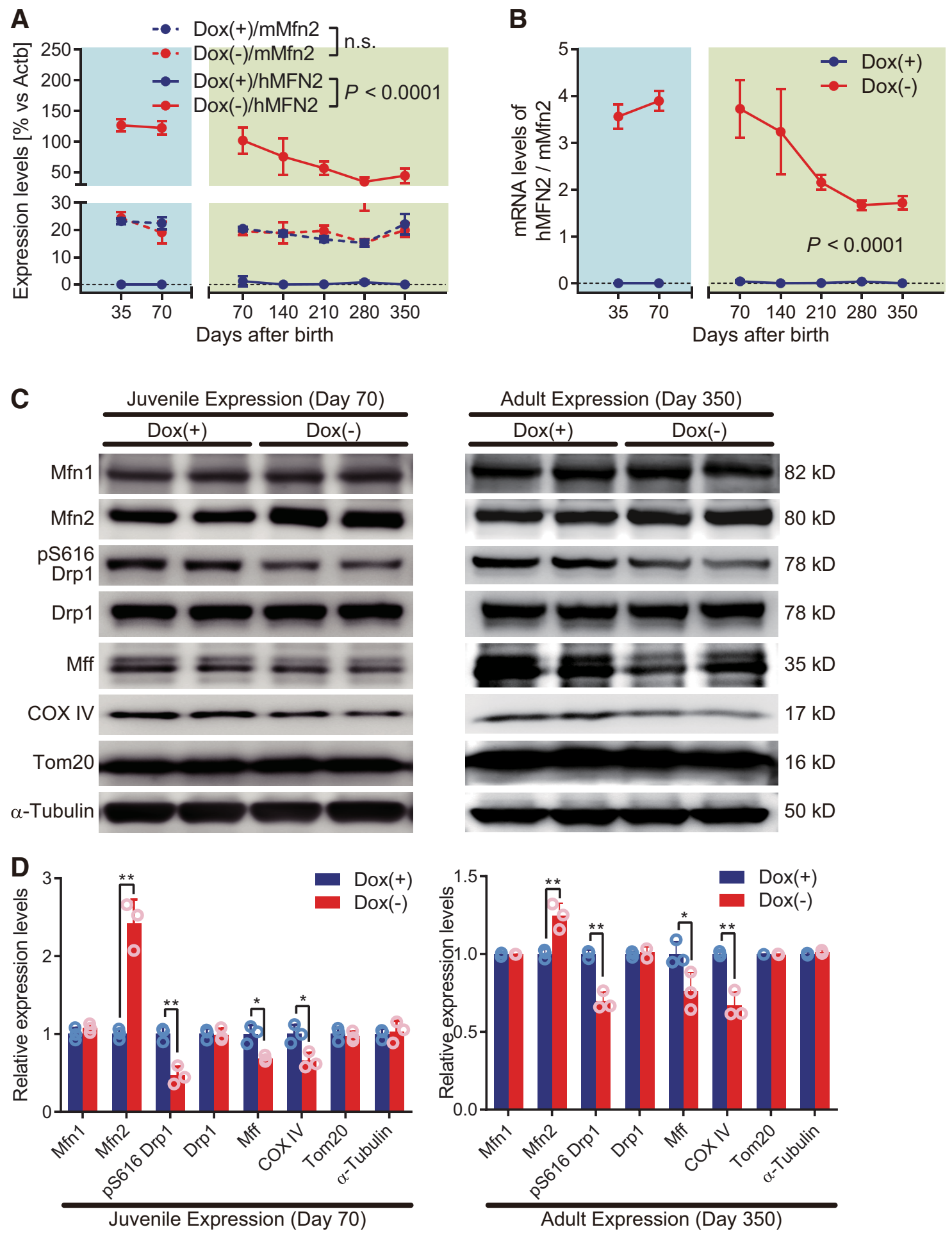

Figure 2. Characterization of the Camk2a-tTA/TRE-hMFN2(D210V) mouse line. $\boldsymbol{A}$, mRNA expression levels of $\mathrm{m} M$ fn2 and hMFN2 in the cortex compared with $\beta$-actin ( $A c t b$ ) by $\Delta \Delta C t$ method. $\boldsymbol{B}$, Expression of $\mathrm{h} M F N 2$ compared with endogenous $\mathrm{mMfn} 2$. The left and right sides highlighted in blue and green in $(\boldsymbol{A})$ and $(\boldsymbol{B})$ show the results from the juvenile expression and adult expression groups, respectively. $P$ values calculated by two-way ANOVA are shown in graph. $\boldsymbol{C}$, Representative results of protein expression levels in the cortex by Western blot analysis and (D) their quantitative evaluation. ${ }^{*} p<0.05,{ }^{* *} p<0.01$ by two-tailed multiple $t$ test $(n=3)$. Detailed statistical parameters are shown in Figure $2-1$, available at https://doi.org/10.1523/JNEUROSCI.2139-18.2018.f2-1.

have not been induced at this time point (Fig. 4B-H), we hypothesized that the first abnormality induced after hMFN2(D210V) expression was mitochondrial aggregation, which was followed by other abnormalities.

In patients with a family history of hMFN2(D210V), increased mtDNA instability and multiple deletions were observed in the diseased muscle tissue (Rouzier et al., 2012). In addition, increased frequency of mtDNA deletions has been reported in $M f n 1$ and $M f n 2$ muscle tissue-specific knock-out mice (Chen et al., 2010). Therefore, we performed long-range PCR to detect any mtDNA deletions. Although the amount of mtDNA deletion varied among individuals, all the mtDNA visualized in the 

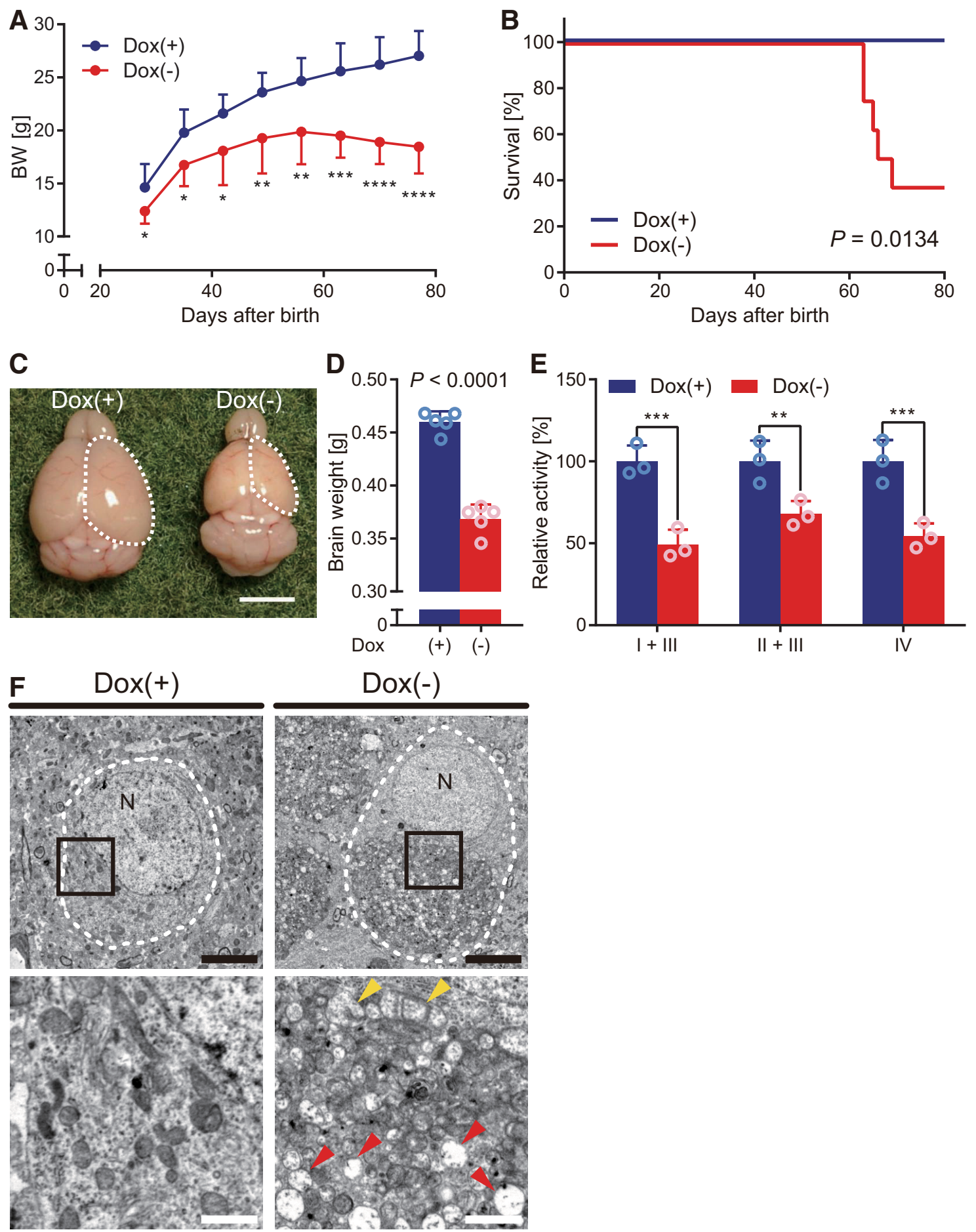

Figure 3. Juvenile expression of hMFN2(D210V) induces acute and severe phenotypes. $A$, Transition of body weight from 4 weeks after birth. Data represented as mean $\pm S D$. ${ }^{*} p<0.05$, ${ }^{* *} p<$ $0.01,{ }^{* * *} p<0.001,{ }^{* * * *} p<0.0001$ by two-tailed multiple $t$ test $(n=8)$. B, Survival curve by Kaplan-Meier method is shown. The $p$ value indicated in the graph is the result of the log-rank test. $\operatorname{Dox}(+)$ group, $n=7$; $\operatorname{Dox}(-)$ group, $n=8$. C, Representative images of brains extracted from mice at 10 weeks of age. Marked cortex (surrounded by dashed line) atrophy was observed in a brain from the Dox $(-)$ group. Scale bar, $5 \mathrm{~mm}$. $\boldsymbol{D}$, Brain weight at 10 weeks of age. Data are represented as mean $\pm S D$. The $p$ value calculated by independent two-tailed $t$ test is shown in the graph. $\boldsymbol{E}$, Respiratory complex activities at 10 weeks of age. Data are represented as mean $+S D .{ }^{* *} p<0.01,{ }^{* * *} p<0.001$ by two-way ANOVA $(n=3)$. Detailed statistical parameters are shown in Figure 2-1, available at https://doi.org/10.1523/JNEUROSCI.2139-18.2018.f2-1. $\boldsymbol{F}$, Representative electron microscopy images of the hippocampal CA1 region. Bottom, High-magnification images of the areas surrounded by black borders in the top. The white dashed lines are the borders of one neuronal cell and $\mathrm{N}$ is the nucleus, respectively. Yellow and red arrowheads indicate mitochondria with abnormal inner membranes and swollen mitochondria lacking inner membrane structures, respectively. Scale bars: black, $5 \mu \mathrm{m}$; white, $1 \mu \mathrm{m}$.

adult expression group had at least some degree of deletion (Fig. 5E).

An abnormal accumulation of proteins, such as amyloid and tau, is often a hallmark of neurodegenerative diseases in humans.
As such, we measured amyloid to investigate whether the neurodegeneration observed in this mouse model is related to the abnormal accumulation of proteins. Although we found low amounts of protein compared with the frequency of amyloid 
A

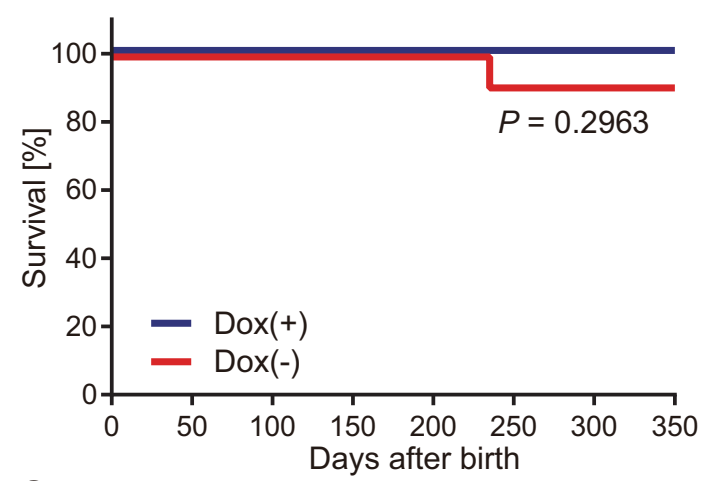

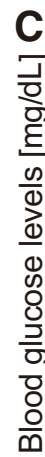

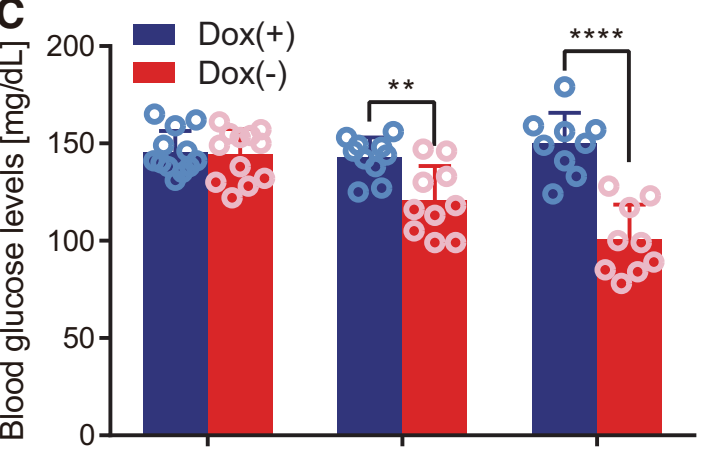

Day 210

Day 280

Day 350

E
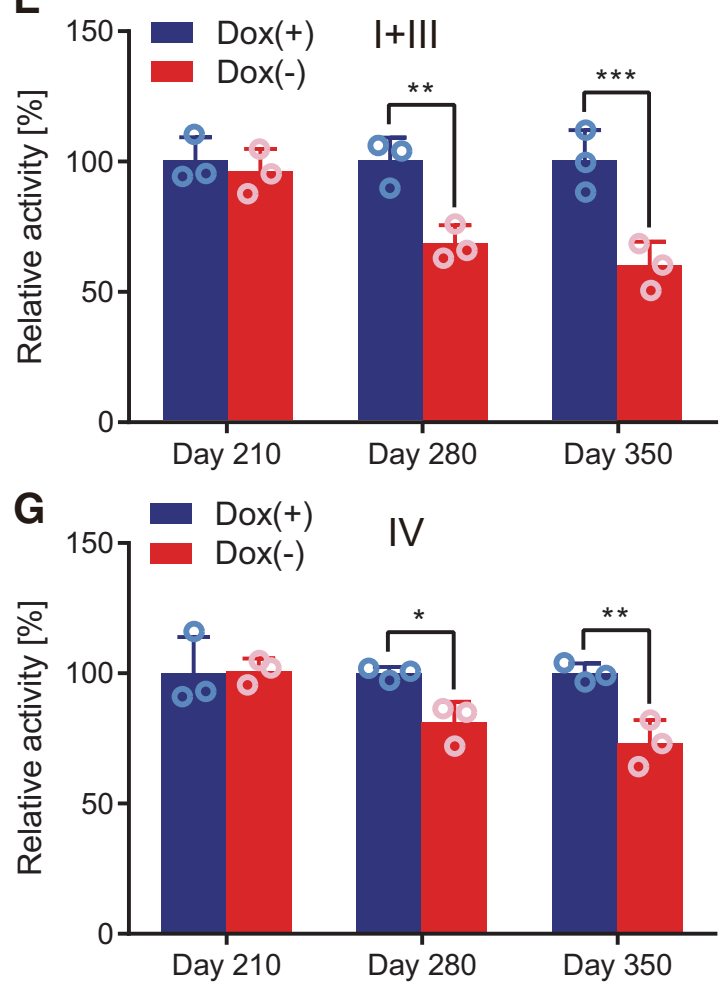

B
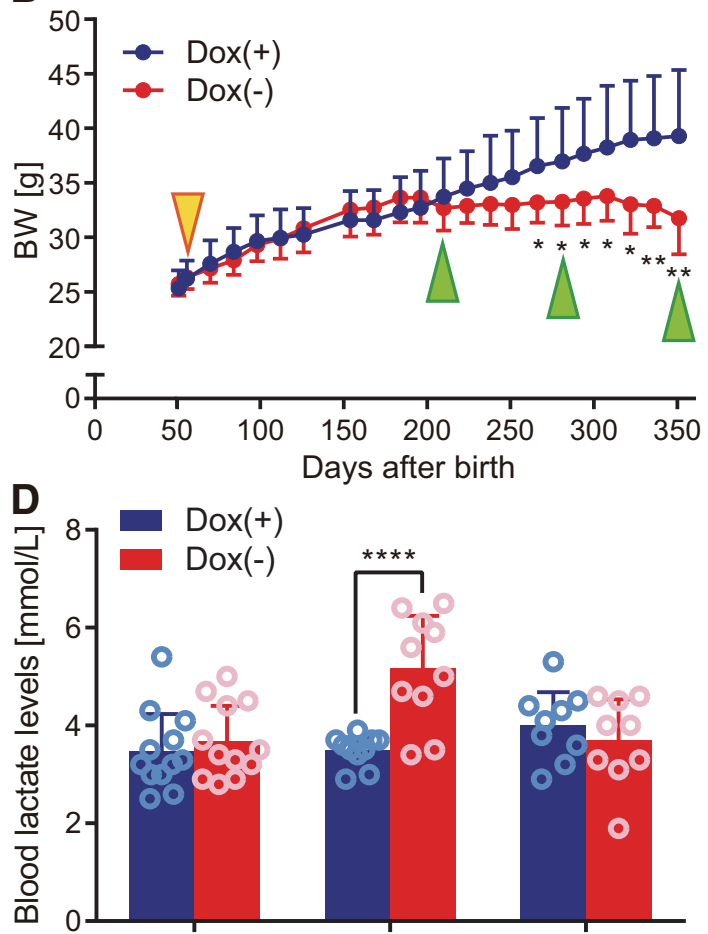

Day 210

Day 280

Day 350

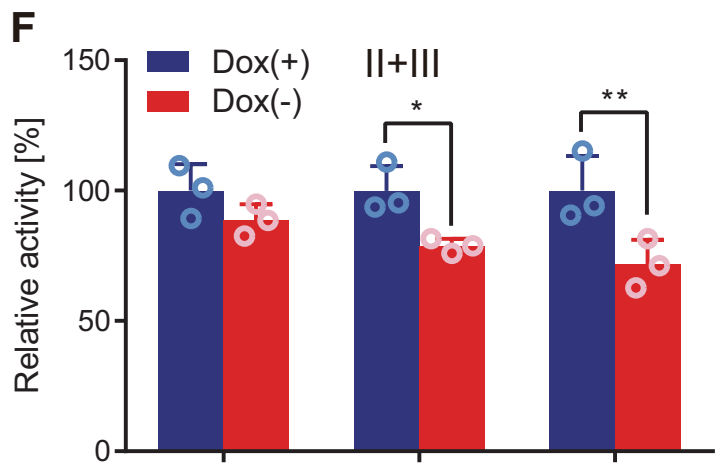

Day 210

Day 280

Day 350

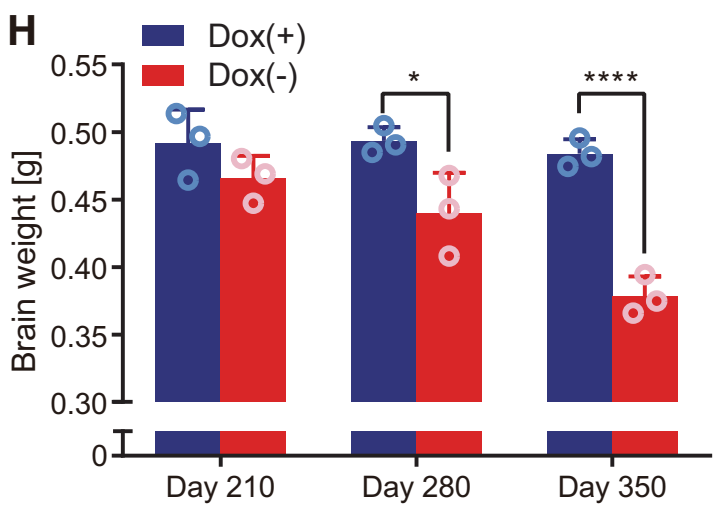

Figure 4. Adult expression of hMFN2(D210V) induces delayed but progressive phenotypes. $A$, Survival curve by Kaplan-Meier method is shown. The $p$ value indicated in the graph is the result of the log rank test. Dox $(+)$ group, $n=12 ; \operatorname{Dox}(-)$ group, $n=11 . B$, Transition of body weight. Yellow arrowhead indicates the time point when expression of hMFN2(D210V) started and green arrowheads show the time points when physiological and biochemical analyses were performed. Data represented as mean $\pm S D .{ }^{*} p<0.05,{ }^{* *} p<0.01$ by two-tailed multiple $t$ test. $C$, Blood glucose levels, $(\boldsymbol{D})$ blood lactate levels, $(\boldsymbol{E}-\boldsymbol{G})$ biochemical activities of respiratory complexes in cortex, and $(\boldsymbol{H})$ brain weights at Days 210,280 , and 350. Data represented as mean + SD. ${ }^{*} p<0.05$, ${ }^{* *} p<0.01,{ }^{* * *} p<0.001,{ }^{* * *} p<0.0001$ by two-way ANOVA. Detailed statistical parameters are shown in Figure 2-1, available at https://doi.org/10.1523/JNEUROSCI.2139-18.2018.f2-1. 
A

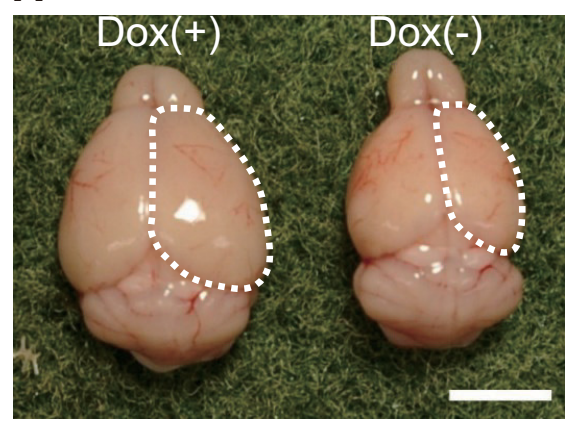

B
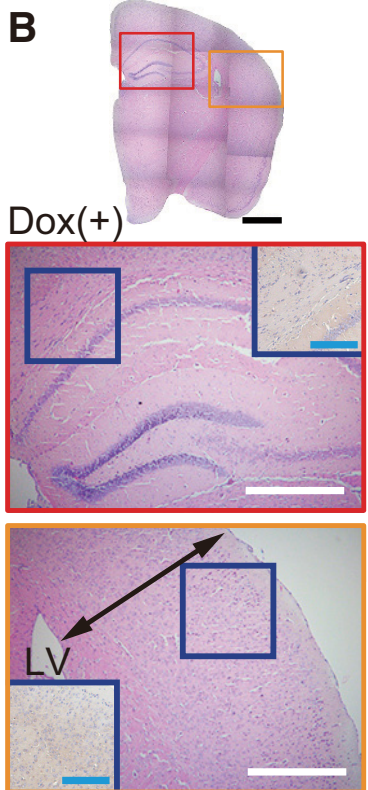

$\operatorname{Dox}(-)$

C $\operatorname{Dox}(+)$
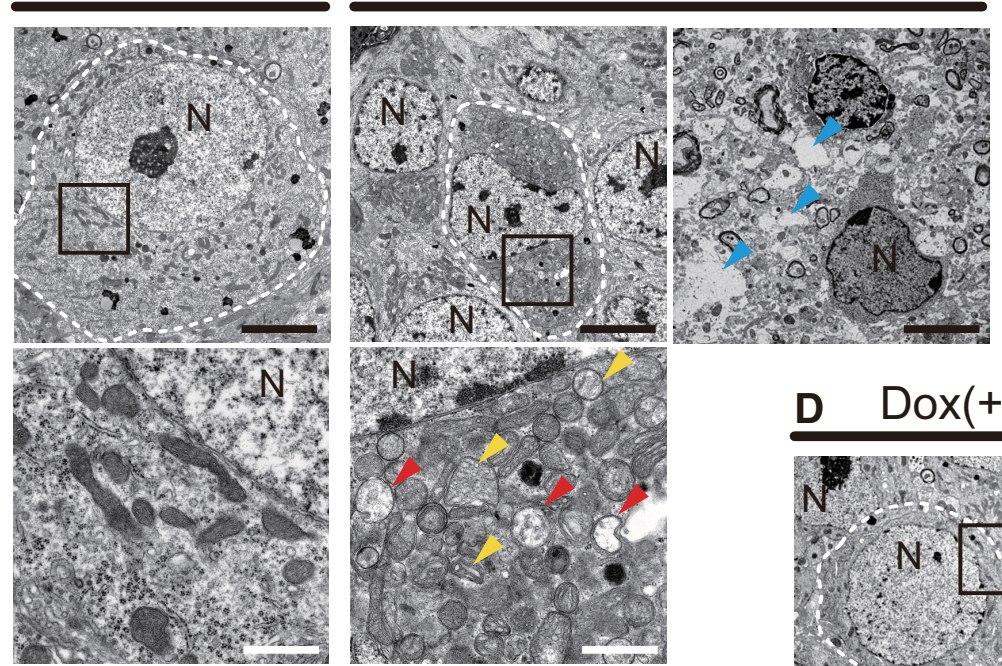

E

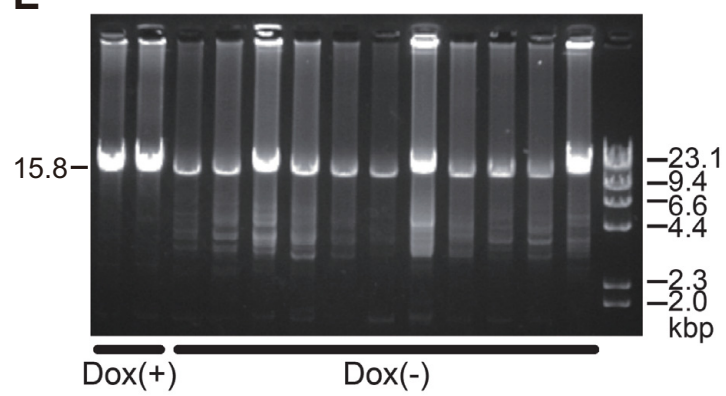

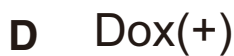
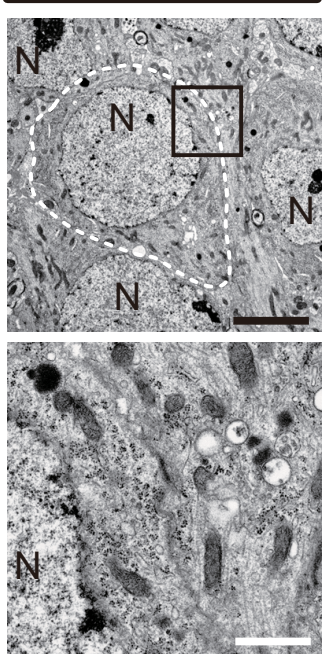
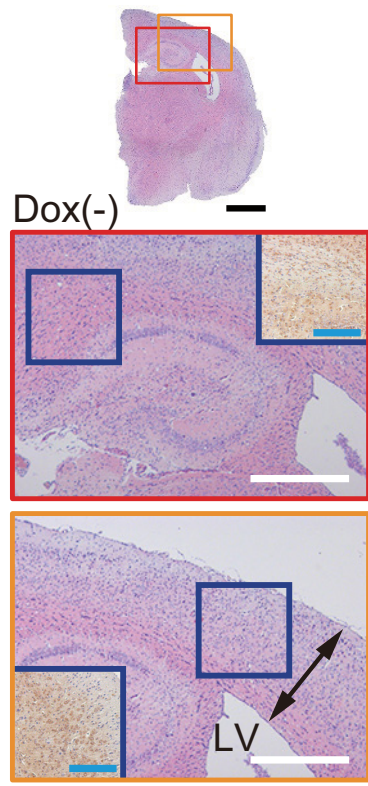

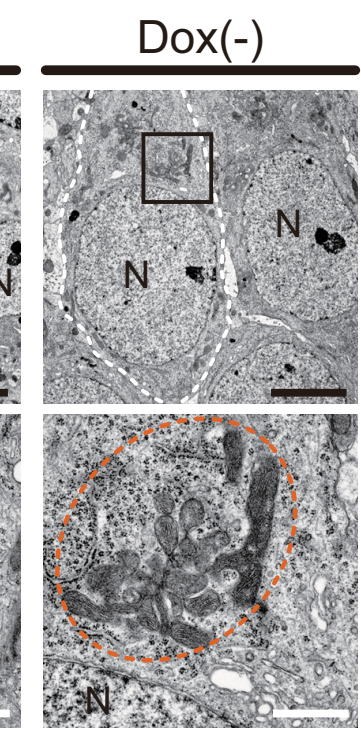

Figure 5. Brain histopathological analyses of adult expression group mice. $A$, Representative images of brains extracted from mice at Day 350 . Marked cortical (surrounded by dashed line) atrophy was observed in a brain from the Dox (-) group. Scale bar, $5 \mathrm{~mm}$. B, Representative coronal sections around bregma $-1.70 \mathrm{~mm}$. Top, Hematoxylin-eosin (HE) staining of whole-brain hemispheres. Middle and bottom, High-magnification images of areas surrounded by red (hippocampus) and yellow (cortex) borders in top, respectively. In the Dox(-) group, the cortical thickness (bottom, arrows) becomes thinner by $\sim 50 \%$ compared with the Dox $(+$ ) group, and an enlarged lateral ventricle (LV) was observed. In the middle and bottom, results from $\mathrm{m} 1 \mathrm{~A}$ immunohistochemical staining of areas surrounded by navy borders are also shown. Scale bars: black, $1 \mathrm{~mm}$; white, $500 \mu \mathrm{m}$; blue, $200 \mu \mathrm{m}$. C, D, Representative electron microscopy images of hippocampal CA1 region at (C) Day 350 and (D) Day 140. Bottom, High-magnification images of areas surrounded by black borders in top. White dashed lines mark the borders of one neuronal cell and $\mathrm{N}$ is the nucleus, respectively. Yellow and red arrowheads in $(\boldsymbol{C})$ indicate mitochondria with abnormal inner membranes and swollen mitochondria lacking inner membrane structures, respectively. Blue arrowheads in $(\boldsymbol{C})$ show gaps generated in the tissue because of progressed neurodegeneration. Mitochondria surrounded by an orange dashed line in $(\boldsymbol{D})$ are aggregated; however, the aggregation is not tight compared with $(\boldsymbol{C})$, and they maintained normal morphology and inner membrane structures. Scale bars: black, $5 \mu \mathrm{m}$; white, $1 \mu \mathrm{m}$. E, MtDNA extracted from the cortex was amplified by long PCR. In the Dox(-) group, unspecified smaller bands were detected simultaneously with the $15.8 \mathrm{kbp}$ main band. 
plaques that are detected in Alzheimer's disease (Nordberg, 2004), amyloid-specific birefringence was observed in the hippocampal region of the adult-expressing group (Fig. 6).

\section{Adult expression of hMFN2(D210V) induces abnormal motor function}

The cerebral cortex, which was severely damaged by adult expression of hMFN2(D210V), is responsible for many higher-order functions, such as perception, thought, memory, and the control of motor function. We focused on investigating motor function in the adult-expressing group after Day 300. First, we performed the hanging wire test. The latency to fall in the mutant-expressing group was shorter than in non-expressing group (Fig. 7A), although those mice had lower body weights than the nonexpressing group (Fig. 4B). In addition, grip strength was significantly reduced in the mutant-expressing group (Fig. $7 B$ ). The muscle fibers of the quadriceps femoris and the tibialis anterior muscles, which are heavily involved in walking motion, were comparatively smaller in the mutant-expressing than the nonexpressing group (Fig. 7C). Characteristic findings of muscle atrophy, such as discrepancies in size and small angular fibers, were observed upon histological examination (Fig. 7D). Moreover, abnormalities in lower limb stretch reflexes that are signs of paralysis were observed during suspension (Fig. $7 E$ ). Extensive atrophy was observed in cerebral cortex, including the motor cortex region; therefore, we hypothesize that upper motor neurons may have been significantly affected. There were no obvious abnormalities in lower motor neurons in the anterior horn of the spinal cord (Fig. $7 F$ ), and there was no distinctive denervation in muscle tissue, such as small and large group atrophy; however, it is possible that neurogenic muscle atrophy was induced from pyramidal tract disorder.

Next, we performed the beam-walking test, which measures walking speed and the number of foot slips on a rod until the destination is reached, as a measure of motor coordination. Control mice were able to proceed smoothly with almost no slips. In contrast, the mutant-expressing mice recorded many instances of foot slips and slower walking speeds (Fig. 7G,H) when a wide rod was used. After the rod was changed to a narrow one, the control mice moved at slower speeds with increased slips and the difference between groups was reduced. These results clarified that the adult expression of hMFN2(D210V) causes myofiber atrophy and reduced cooperative motor function.

\section{Adult expression of hMFN2 (D210V) induces abnormal behavior}

Next, we analyzed the effect of adult hMFN2(D210V) expression on locomotor activity. In contrast to the reduced muscle strength and paralysis observed in the mutant-expressing mice, there was an abnormal increase in activity level in the home cage assessment. In the mutant-expressing group, we observed significantly elevated activity levels during the daytime and, more remarkably, during the night (Fig. 8A). Similar to our findings from the home cage assessment, the open-field test also revealed that total distance traveled was significantly elevated in the mutant-expressing group (Fig. 8B). Simultaneously, the amount of rearing activity, generally considered as an indicator of exploratory behavior, was also increased in the mutant-expressing group (Fig. 8C). However, this change correlated with the change in locomotor activity, which indicated that this increase reflected the remarkable hyperactivity, rather than an increased desire for exploring. The amount of time spent in the center area was recorded for anxietylike behavior and revealed that there was no difference between the two groups (Fig. 8D). Although there was an abnormal increase in activity level in the mutant-expressing group, there was no significant difference between the two groups in food or water intake, or body temperature (Fig. 8E,F). Previously, decreased locomotor activity was reported in Camk2a-tTA mice because of the effects of an integrated locus of the transgene (McKinney et al., 2008). However, our model that used the same transgene showed hyperactivity. This indicated that the effects of the integrated locus of the transgene were negligible in our experimental system. Consequently, brain damage because of hMFN2(D210V) expression induced behavioral abnormalities, such as extremely pronounced hyperactivity; however, though there was no significant influence on emotional aspects within the examined range.

\section{Adult expression of hMFN2 (D210V) induces impaired cognitive function}

The Barnes maze was used to investigate the effect of adult hMFN2(D210V) expression on learning and memory. The nonexpressing group learned the correct hole and almost directly revisited this hole in subsequent trials (Fig. 9A, i-iii); however, we observed large individual differences in the behavior of hMFN2(D210V)-expressing mice, with frequent visits to the incorrect holes (Fig. 9A, iv), pausing at the incorrect hole (Fig. 9A, $\mathrm{v}$ ), and a lack of locomotor activity throughout the trial period ( 5 min; Fig. $9 A$, vi), which lasted until trial 20 . In the non-expressing group, there was a reduction in the number of visits to incorrect holes as well as the time to find the correct hole; by Trial 8, all of the mice arrived at the correct hole within the designated time (Fig. 9B-D). Throughout the entire trial period, the learning effect was almost absent in the mutant-expressing group and even during the final trial, only half of the mice were able to arrive at the correct hole (Fig. 9B-D). Although a low rate of achievement and a large amount of time was spent in identifying the correct hole in the mutant-expressing group, the average number of visits to incorrect holes was not different between the two groups (Fig. 9B). This was because of inactive individuals who hardly moved during the designated time, as shown in Figure 9A, vi. The results from the Barnes maze suggest a reduction in learning and memory because of hMFN2(D210V) expression; however, some parts of the results were complicated by the observed individual differences in locomotor activity.

Next, we used the T-maze as a simple measure of working memory. This test provides mice with two passages and evaluates how often they select the passage not previously traveled. The non-expressing group had an accuracy rate of $70 \%$ on the first trial with a gradual increase in accuracy with each successive trial, ending at a rate $>80 \%$. The accuracy rate in the mutantexpressing group was $\sim 50 \%$ from the start to the end of the test and there was no tendency of increased correct response with each successive trial (Fig. 9E). In summary, the results of the Barnes maze and T-maze indicated markedly impaired cognitive function as a result of hMFN2(D210V) expression.

\section{Discussion}

In this study, we successfully identified different dysfunctions resulting from the timing of hMFN2(D210V) mutant expression.

Expression of hMFN2(D210V) resulted in a reduction in pS616-Drp1, and Mff expression (Fig. 2C,D). pS616-Drp1 and Mff are mitochondrial fission proteins, and mitochondrial fusion is inhibited by the expression of hMFN2(D210V); therefore, it a reduction in the expression of factors responsible for division was induced to balance mitochondrial fusion and fission. Reduced expression of COX IV, a respiratory chain protein located on the 

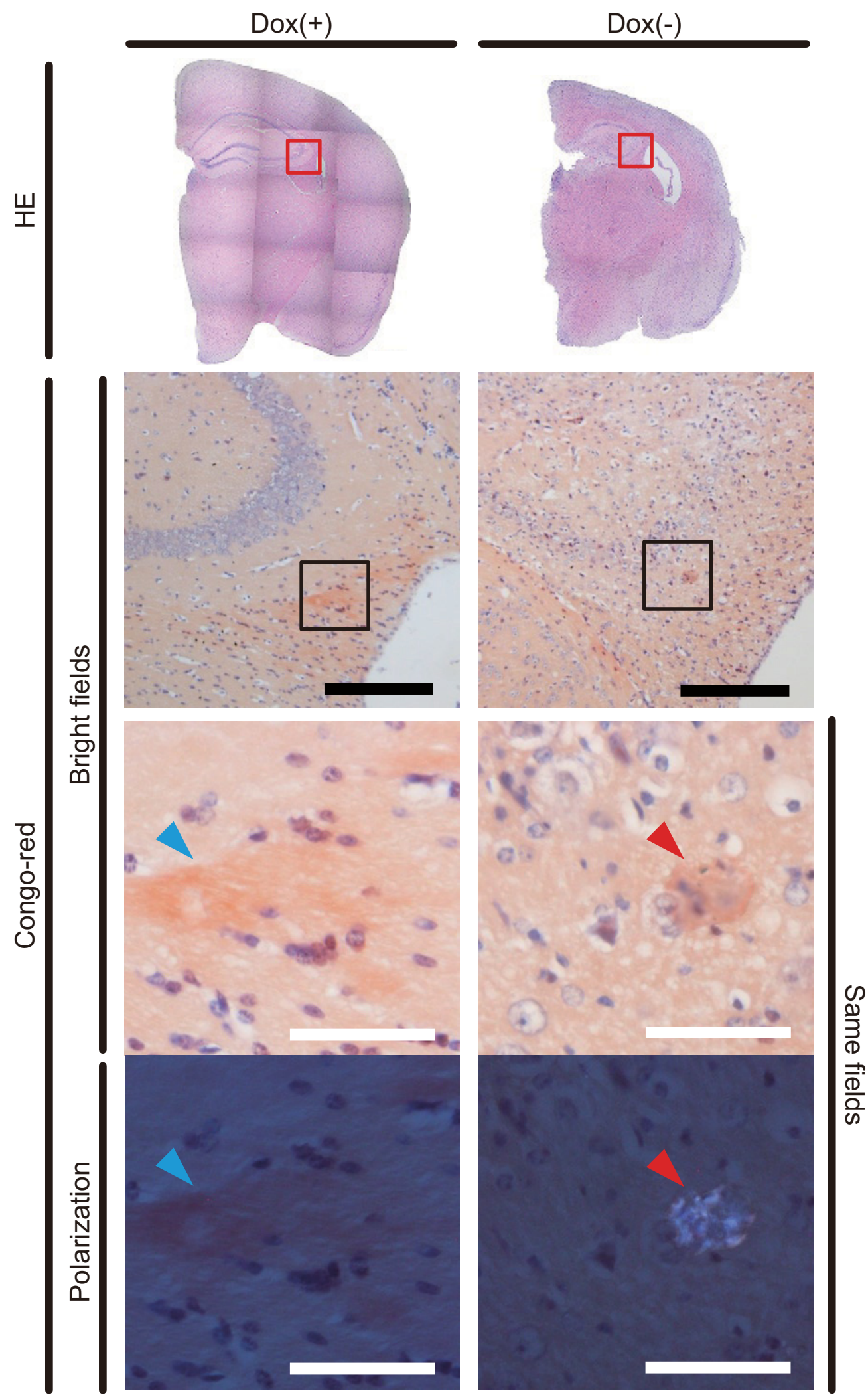

Figure 6. Detection of amyloid plaques in adult expression group mice. Amyloid plaques were detected by Congo-red staining of paraffin sections. The results of the areas surrounded by red borders in the top are shown in the middle. High-magnification images of areas surrounded by black borders in the middle are shown in the bottom as bright-field images and polarized light microscopy images. Although Congo red stains amyloid depositions in red-orange under bright-field light, sometimes similar staining is observed in other areas showing a relatively high pH (blue arrowheads in the Dox (+) control group). Amyloid-specific results from the Congo red stain show an apple-green birefringence under polarized light microscopy (red arrowheads in the Dox( - ) group). The birefringence was not detected in the Dox(+) group; however, it was detected in low-frequency in the Dox( - ) group. Scale bars: black, $200 \mu \mathrm{m} ;$ white, $50 \mu \mathrm{m}$. 

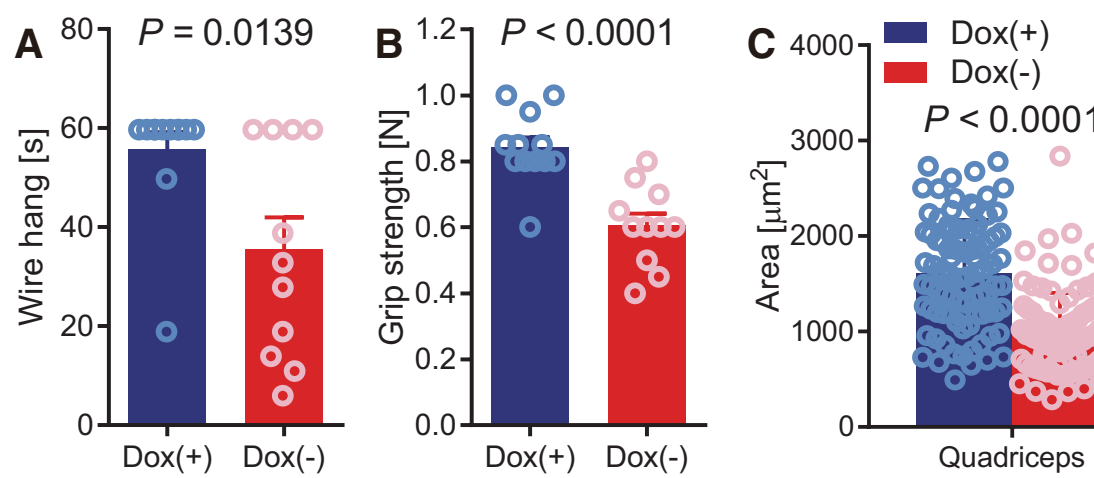

$P<0.0001$
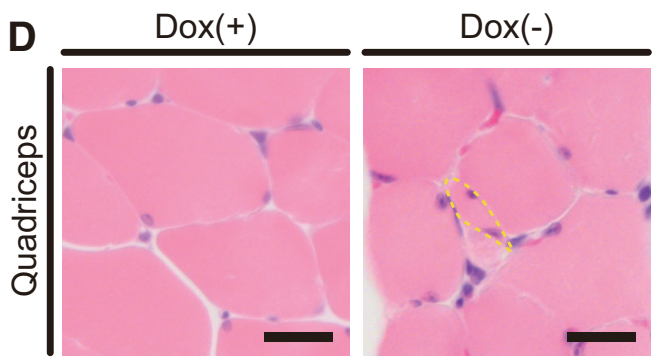

$\mathbf{E}$
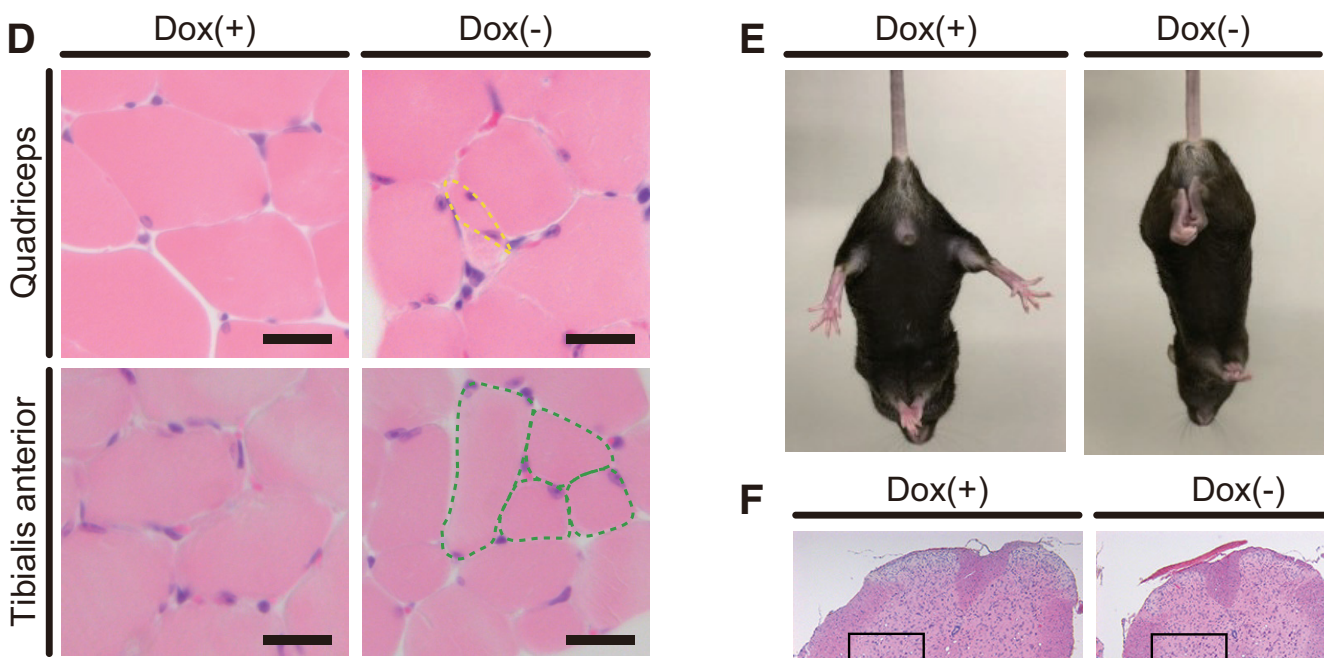

$\mathbf{F}$
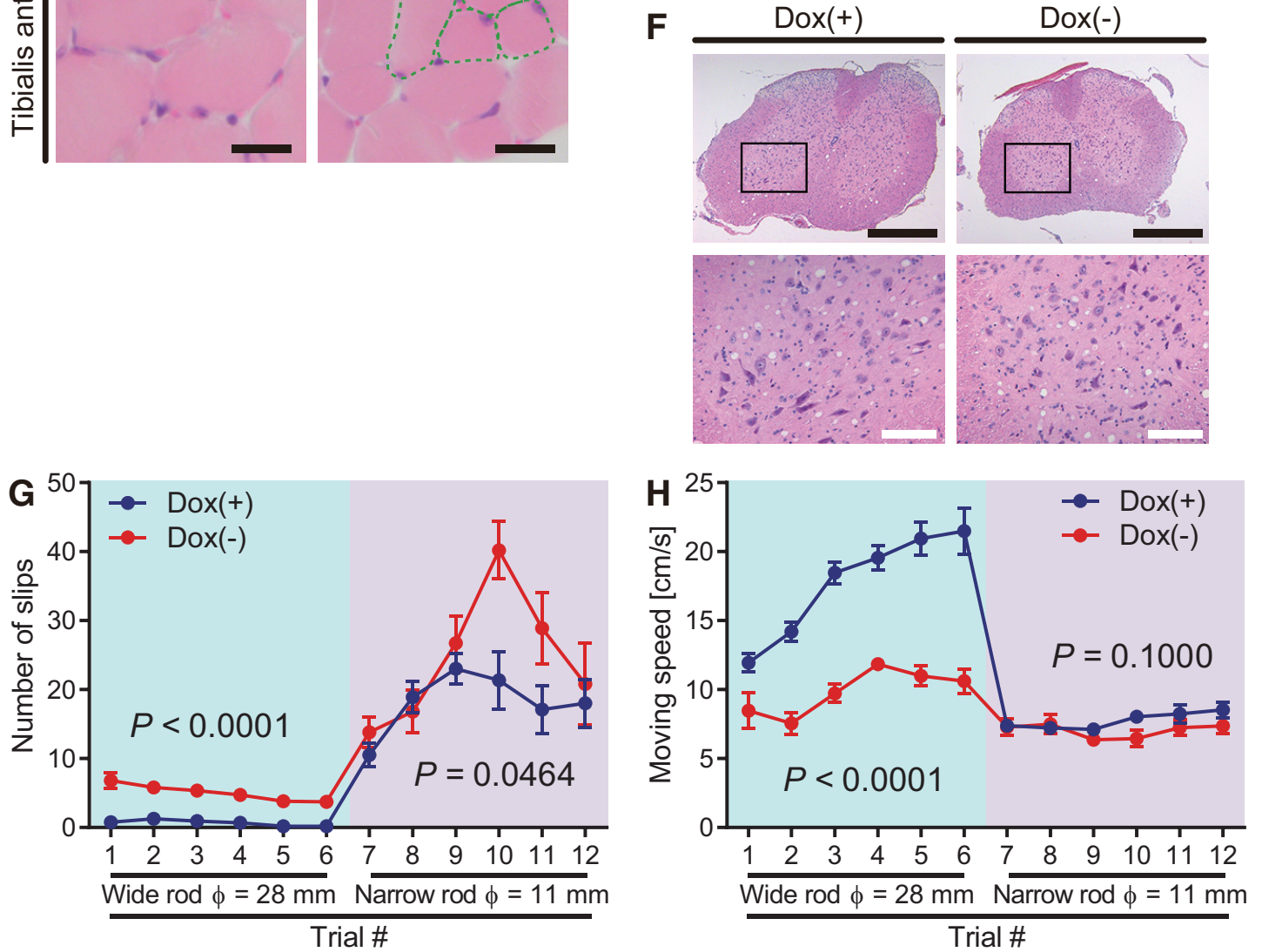

Figure 7. Analyses of motor functions in adult expression group mice. $A$, Wire hang test. Latency to fall was recorded with a $60 \mathrm{~s}$ cutoff time. $\boldsymbol{B}$, Grip strength of forelimbs. Data indicate mean $+S E$. $P$ values calculated by two-tailed Mann-Whitney $U$ test $(\boldsymbol{A})$ or independent two-tailed $t$ test $(\boldsymbol{B})$ are shown in graphs. Dox $(+)$ group, $n=12$; Dox $(-)$ group, $n=11$. $\boldsymbol{C}$, Cross-sectional areas of the quadriceps and tibias anterior. Graphs indicate results from 3 mice per group, 30 fibers per mouse $(n=90$, in total). $P$ values calculated by independent two-tailed $t$ test are shown in graphs. $\boldsymbol{D}$, Representative HE staining cross-sections of the quadriceps and tibias anterior. The yellow dashed line is a fiber with small angular tendencies, and the green dashed lines indicate fibers with size discrepancies. Scale bars, $20 \mu \mathrm{m}$. $\boldsymbol{E}$, Representative images of limb reflexes during tail hanging. Whereas Dox $(+)$ mice have stretched legs, a reflex to balance themselves, Dox $(-)$ mice lack such reflex. $\boldsymbol{F}$, Representative images of cross-sections of the lumber spinal cord (top). The magnified views of the anterior horn regions (bottom) shows remaining of motor neurons (pyramidal shaped cells) in both Dox $(+)$ and Dox $(-)$ groups. Scale bars: black, 500 $\mu \mathrm{m} ;$ white, $100 \mu \mathrm{m}$. $\boldsymbol{G}$, The number of slippages and $(\boldsymbol{H})$ moving speed recorded during the balance beam test. A wide rod was used in the first six repetitions and a narrow one was used in the remaining six repetitions. Data represented as mean \pm SE. $P$ values calculated by repeated-measures ANOVA in the first and later six repetitions are shown in graphs. Dox $(+)$ group, $n=12 ; \operatorname{Dox}(-)$ group, $n=11$. Detailed statistical parameters are shown in Figure 2-1, available at https://doi.org/10.1523/JNEUROSCI.2139-18.2018.f2-1. 
A

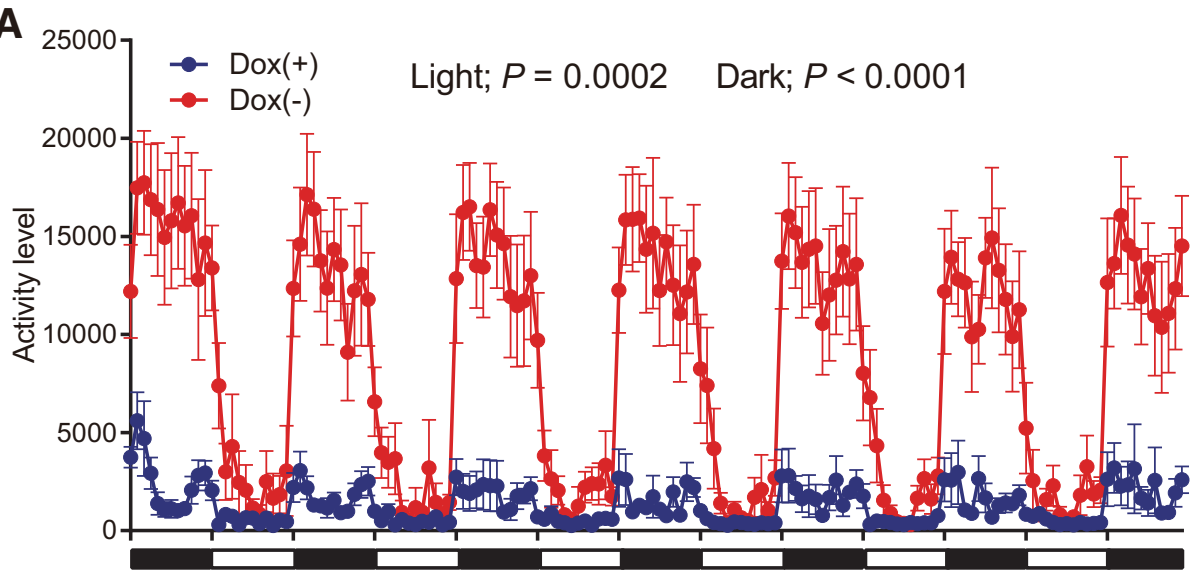

B

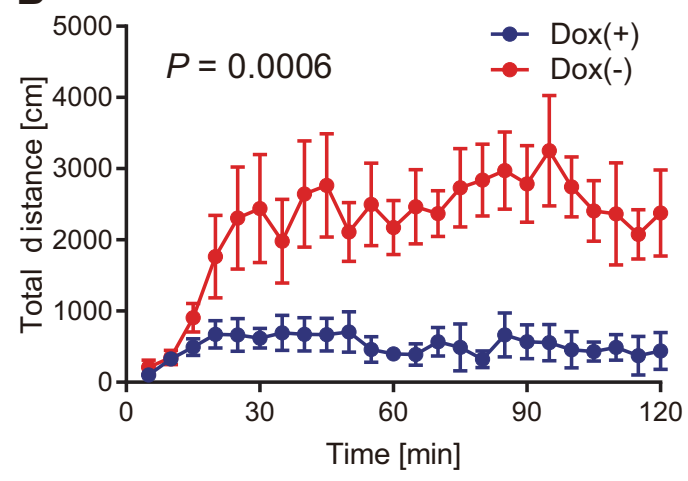

D
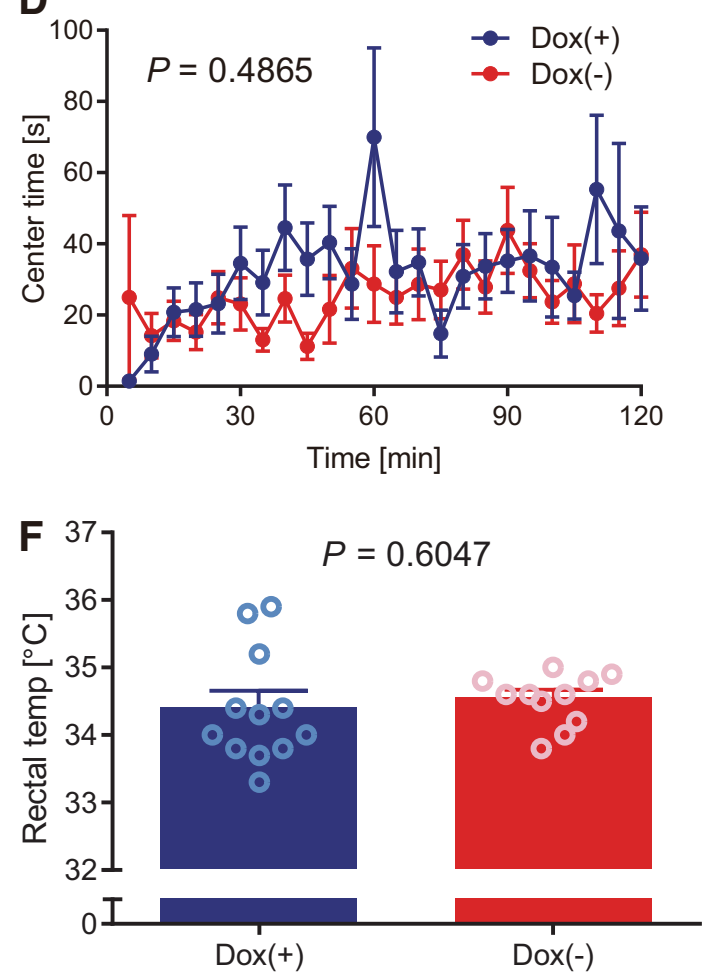

C

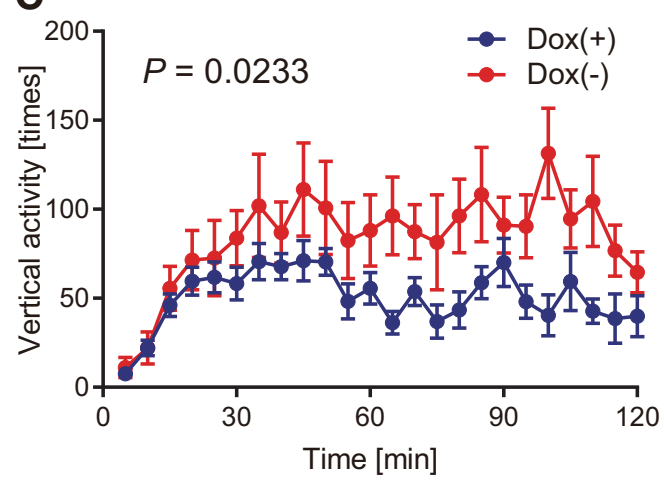

E

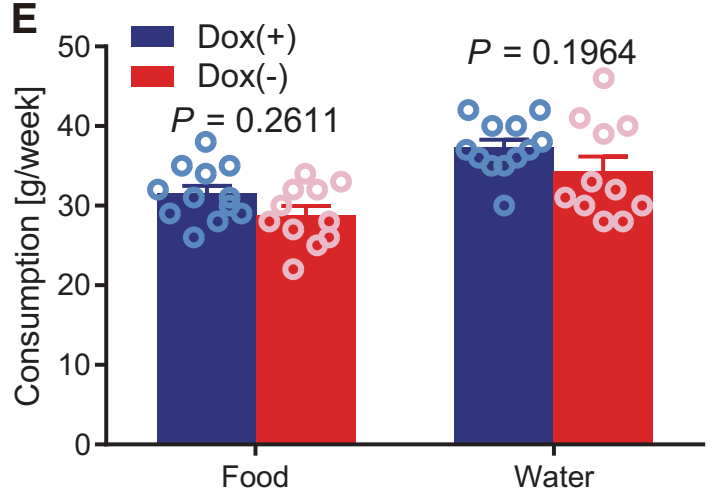

Figure 8. Analyses of behavior of mice expressing hMFN2(D210V) during adulthood. $\boldsymbol{A}$, Results from the home cage test. Each mouse was individually housed in each home cage and their locomotor activity was monitored. White and black bands shown under the $x$-axis indicate daytime and night time, respectively. $\boldsymbol{B}$, Distance traveled, $(\boldsymbol{C})$ rearing time, and $(\boldsymbol{D})$ time spent in the center area was recorded every 5 min during the open-field test. Data represents the mean $\pm S E$. $P$ values calculated by repeated-measures ANOVA are shown in graphs. Dox $(+)$ group, $n=12 ; \operatorname{Dox}(-)$ group, $n=11$. $\boldsymbol{E}$, Food intake and water consumption per week. $\boldsymbol{F}$, Rectal temperature. Data represented as mean + SD. $P$ values calculated by two-tailed multiple $t$ test $(\boldsymbol{E})$ and independent two-tailed $t$ test $(\boldsymbol{F})$ are shown in graphs. Dox $(+)$ group, $n=12$; Dox - group, $n=11$. Detailed statistical parameters are shown in Figure 2-1, available at https://doi.org/10.1523/JNEUROSCI.2139-18.2018.f2-1. 
A

Trail \#20

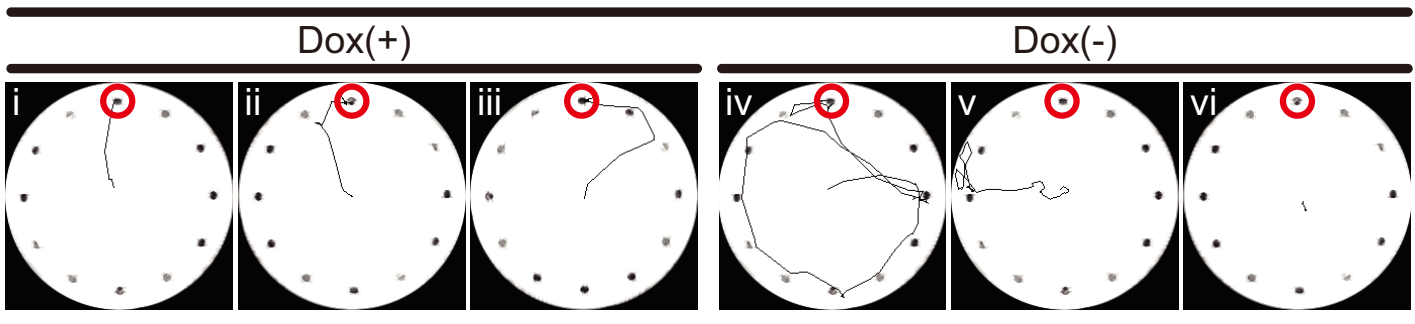

B

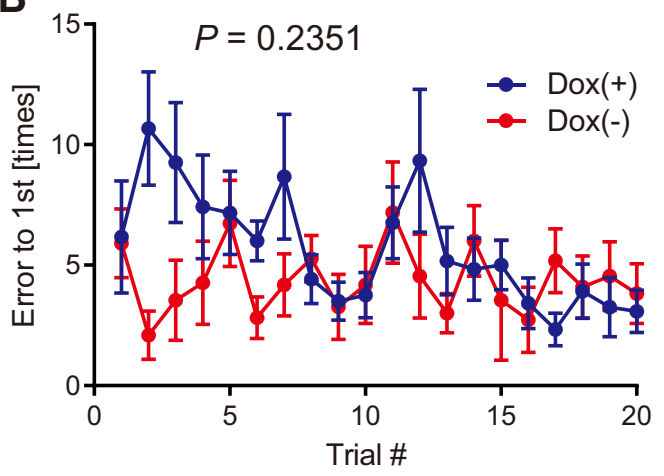

D

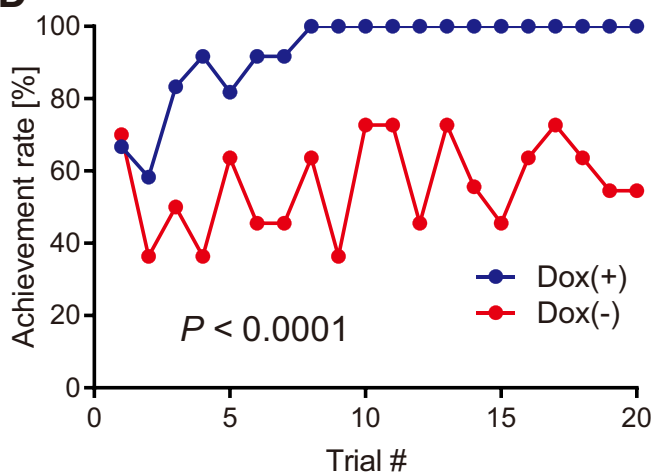

C

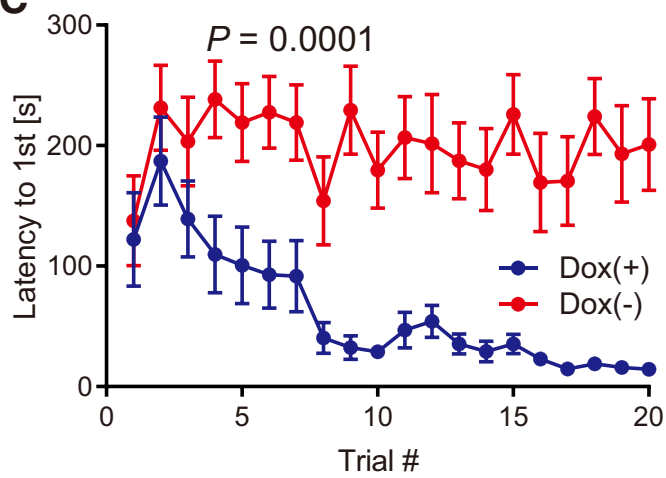

E

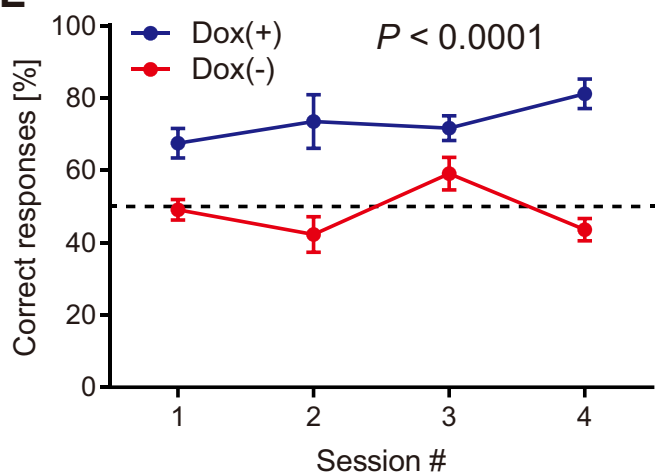

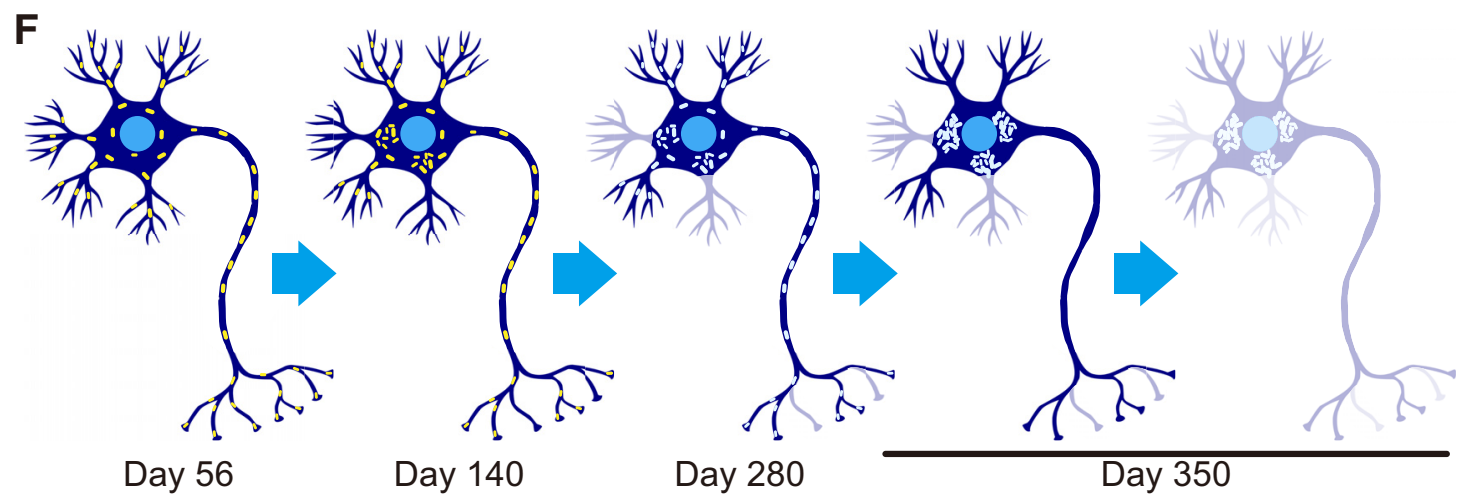

Figure 9. Evaluation of spatial/working memory and learning in adult expression group mice. $A$, Representative traces of mouse movements during the 20th trial of the Barnes maze test. Red circles indicate the correct holes for mice. Transition of $(\boldsymbol{B})$ number of visiting error holes before arriving at the correct hole, $(\boldsymbol{C})$ time to arrive at the correct hole, and $(\boldsymbol{D})$ rate of mice that arrived at the correct hole within the time limit in each trial of the Barnes maze test. $\boldsymbol{E}$, The rate at which mice select the correct path in the T-maze. The dashed line indicates a chance level (50\%). Data represented as mean \pm SE. $P$ values calculated by repeated-measures ANOVA are shown in graphs. Dox $(+)$ group, $n=12$; $\operatorname{Dox}(-)$ group, $n=11$. Detailed statistical parameters are shown in Figure 2-1, available at https://doi.org/10.1523/JNEUROSCI.2139-18.2018.f2-1.F, Schematic illustration of the predicted neurodegeneration mechanism in mice expressing hMFN2(D210V) during adulthood. Mitochondrial aggregation is the first abnormality induced by hMFN2(D210V) expression, interfering normal mitochondrial distribution to synapses and dendrites ( $\sim$ Day 140 ). Mitochondria-lacking synapses and dendrites cannot be maintained, and mitochondrial respiration gradually decrease because damage-buffering system by mitochondrial fusion is disrupted ( $\sim$ Day 280). Long-term continuation of these states leads to neurodegeneration ( Day 350). 
mitochondrial inner membrane, was also observed. Abnormalities and deletions were observed in the inner mitochondrial membrane of the mutant-expressing group (Figs. $3 F, 5 C$ ), with a corresponding reduction in the proteins that constitute the respiratory chain, thought to be one of the causes of respiratory dysfunction (Fig. 4E-G).

Deletions in mtDNA within brain tissue was observed; however, the proportion of deletions was not large enough to be considered dominant compared with wild-type mtDNA (Fig. 5E). Previous research on a large-scale mtDNA deletion $(\Delta \mathrm{mtDNA})$ in mouse models of mitochondrial diseases (mito-mice $\Delta$ ) found that if the accumulation of $\Delta \mathrm{mtDNA}$ within tissue was not above $\sim 60-70 \%$, there was no effect on respiratory function (Nakada et al., 2001). Although expression of hMFN2(D210V) can induce mtDNA instability as reported in human cases (Rouzier et al., 2012), resultant mtDNA deletions are not considered direct causes of the reduction in respiratory function.

Reduced blood glucose levels concurrent to reduced respiratory function were also observed in the mutant-expressing group (Fig. 4C). In some mitochondrial diseases, diabetes may be comorbid with mitochondrial respiratory dysfunction (Wallace, 1999). Moreover, mitochondrial function is extensively involved in pancreatic insulin secretion (Wiederkehr and Wollheim, 2012); thus, the idea that mitochondrial dysfunction plays a role in hyperglycemia is pervasive. However, in this study, we assumed that as neuronal mitochondrial function decreases, the consumption of sugar in the brain increases, inducing hypoglycemia in mice. Similar hypoglycemia has been observed in mitomice $\Delta$ (Nakada et al., 2004; Ogasawara et al., 2010). We observed a transient increase in lactate levels, after which the difference between the groups was eliminated (Fig. 4D, Days 280 and 350). The transient increase in lactate values is thought to reflect the overproduction of lactic acid because of the acceleration of glycolysis. It is known that brain tissue can use lactic acid as a direct energy source (van Hall et al., 2009). Thus, our results suggest that the change in blood lactate levels of the mutant-expressing group results from the adaptation of brain tissue to positively incorporate the overproduced lactic acid and use it as an energy source.

In addition to biochemical changes, the mutant mice were significantly affected in various biofunctions controlled by the brain, including motor function (Fig. 7) and behavior-pronounced hyperactivity (Fig. 8). The cause of the extreme hyperactivity in this mouse model is unclear; however, the regions with extensive atrophy, specifically the cortex, hippocampus, and dentate gyrus, have high lemur tyrosine kinase 3 ( Lmtk3) expression. Lmtk3 is a candidate gene for hyperactivity (Inoue et al., 2014); thus, a reduction in neural activation within these regions may be related to the phenotypic hyperactivity in our mouse model. Contradictory to the hyperactivity clearly observed in the home cage assessment and open-field test (Fig. $8 A, B$ ), individuals in the mutant-expressing group hardly moved during the Barnes maze (Fig. 9A, vi). However, the results from the open-field test reveal that the activity levels were not different between the control and mutant-expressing groups just after the start of observation (Fig. 8B). This indicates that mutant-expressing mice are not hyperactive when they are initially in a novel environment; hyperactivity only appears after habituation (10-15 min). Thus, during the Barnes maze trial period (maximum of 5 min per trial), there were some mice that hardly moved, and the hyperactive tendencies of the mutant-expressing group were not observed. Impaired working memory was also confirmed using the T-maze (Fig. 9E). These phenotypes are consistent with the ob- served atrophy in regions important for working memory such as hippocampus and cortex, which is a component of the frontal lobe (Fig. 5A-C).

Mitochondrial aggregation was observed before neurodegeneration in these mice (Fig. 5D). We hypothesized that this aggregation is not accompanied with an increase in mitochondria because the expression of the mitochondrial outer membrane protein, Tom 20, was not significantly altered in the $\operatorname{Dox}(-)$ group (Fig. 2C,D). Recently, similar mitochondrial aggregation was reported in Drosophila models of CMT2A (El Fissi et al., 2018). In that paper, the authors suggest that mutated MFN2 that is present in the GTPase domain (or very near the domain) retains the capacity to tether mitochondria, but cannot accomplish GTPase activity-dependent membrane fusion. Because the D $210 \mathrm{~V}$ mutation is also present in the GTPase domain, we hypothesize that similar tethering induces progressive mitochondrial aggregation in our model (Fig. 5, from $D$ state to $C$ state). Aggregation of sticky mitochondria interferes with normal mitochondrial distribution to the synapse via axonal transport, and a deficiency in mitochondrial fusion may induce mitochondrial fragmentation and dysfunction. We consider that long-term continuation of these states induced by hMFN2(D210V) expression can lead to neurodegeneration (Fig. 9F).

The late onset phenotypes observed in mice with post-adult mutant expression have similarities with human neurodegenerative diseases, such as Alzheimer's disease, characterized by gradual neurodegeneration that significantly influences behavior and cognitive function without leading death in the short-term. There are other significant commonalities, such as the observation of oxidative stress together with tissue degeneration (Butterfield, 2002; Fig. 5B) and post-adult initiation of neurodegeneration. These commonalities are meaningful for the understanding of the mechanisms that underlie neurodegeneration in human diseases. Therefore, mice expressing hMFN2(D210V) after maturation can be a useful tool for studying the progress of human age-related neurodegenerative diseases. Another finding common to human neurodegenerative diseases is the detection of amyloid plaque aggregation (Fig. 6); however, this was infrequent, so it is unlikely that amyloid plaques are the cause of large-scale neurodegenerative changes in our model. Recently, it was reported that endogenous amyloid- $\beta$ increases in the brain with aging, even in wild-type mice (Ahlemeyer et al., 2018). Endogenous amyloid in mice might thus appear as a result, rather than a cause, of neurodegeneration (Chui et al., 1999).

The present study demonstrated the indispensability of Mfn2 in the maintenance of neurons throughout life. Our results also confirmed the pathogenicity of the hMFN2(D210V) mutation, which has been reported as a cause of neuromuscular diseases in a human family (Rouzier et al., 2012), using a mouse model. The effect of Mfn2 dysfunction was particularly critical during the juvenile stage, which is a significant period of neural network development, and dysfunction during this time endangered the survival of not only neurons, but also individuals. Of note, there were many similarities between age-related neurodegenerative diseases and the dysfunction observed in hMFN2(D210V) expression after the maturation of neurons. This leads to two important considerations. The first is that there are probably abnormalities in mitochondrial morphology, location, and function as primary or secondary factors driving many neurodegenerative diseases of unknown etiology. There have been several reports of the co-observation of neurodegeneration and abnormalities in mitochondrial dynamics in Alzheimer's and Parkinson's diseases in humans (Reddy et al., 2011), and the normalization of these observations has led to improvements in 
the pathology of mouse models (Manczak et al., 2016; Baek et al., 2017). This suggests that there is a universal relationship between mitochondrial dynamics and neurodegeneration (Franco et al., 2016). Treatment strategies that normalize mitochondrial dynamics may be effective for a wide range of neurodegenerative diseases. Another consideration is the onset timing of etiology in animal models of neurodegenerative disease. Most animal models of neurodegenerative diseases express the human etiologic factors in the brain through transgenic or knock-in techniques, or lack important factors to maintain the function of normal neurons by knock-out techniques. In these models, the effects of the transgenic/knock-in or knock-out start from the fetal stage or just after birth. However, in these situations, discriminating between the acute and serious effects on young neurons and the delayed and progressive effects on mature neurons is difficult, and there is a wide discrepancy in the progression of age-related neurodegenerative diseases in humans. The results shown here demonstrate that the same mutant of the same gene induces different severities in pathology depending on the timing of expression. This strongly suggests that the onset timing of the etiologic factor should be considered to establish a model that closely resembles human neurodegenerative diseases.

The mice we generated through this research have enabled us to evaluate the role of mitochondrial dynamics in neurons at various growth stages via controlled expression of the mutant of MFN2. Analysis of the temporal specificity of the effects of a single etiologic factor may enable the clarification of changes in resistance to the same neural stressor and uncover the mechanisms of neurodegeneration beyond the limit of plasticity.

\section{References}

Ahlemeyer B, Halupczok S, Rodenberg-Frank E, Valerius KP, Baumgart-Vogt E (2018) Endogenous murine amyloid-beta peptide assembles into aggregates in the aged C57BL/6J mouse suggesting these animals as a model to study pathogenesis of amyloid-beta plaque formation. J Alzheimers Dis 61:1425-1450. CrossRef Medline

Baek SH, Park SJ, Jeong JI, Kim SH, Han J, Kyung JW, Baik SH, Choi Y, Choi BY, Park JS, Bahn G, Shin JH, Jo DS, Lee JY, Jang CG, Arumugam TV, Kim J, Han JW, Koh JY, Cho DH, Jo DG (2017) Inhibition of Drp1 ameliorates synaptic depression, $\mathrm{A} \beta$ deposition, and cognitive impairment in an Alzheimer's disease model. J Neurosci 37:5099-5110. CrossRef Medline

Bannerman P, Burns T, Xu J, Miers L, Pleasure D (2016) Mice hemizygous for a pathogenic mitofusin-2 allele exhibit hind limb/foot gait deficits and phenotypic perturbations in nerve and muscle. PLoS One 11:e0167573. CrossRef Medline

Barnes CA (1979) Memory deficits associated with senescence: a neurophysiological and behavioral study in the rat. J Comp Physiol Psychol 93:74-104. CrossRef Medline

Butterfield DA (2002) Amyloid $\beta$-peptide (1-42)-induced oxidative stress and neurotoxicity: implications for neurodegeneration in Alzheimer's disease brain. A review. Free Radic Res 36:1307-1313. CrossRef Medline

Cartoni R, Arnaud E, Médard JJ, Poirot O, Courvoisier DS, Chrast R, Martinou JC (2010) Expression of mitofusin 2(R94Q) in a transgenic mouse leads to Charcot-Marie-Tooth neuropathy type 2A. Brain 133:14601469. CrossRef Medline

Chen H, Detmer SA, Ewald AJ, Griffin EE, Fraser SE, Chan DC (2003) Mitofusins Mfn1 and Mfn2 coordinately regulate mitochondrial fusion and are essential for embryonic development. J Cell Biol 160:189-200. CrossRef Medline

Chen H, Vermulst M, Wang YE, Chomyn A, Prolla TA, McCaffery JM, Chan DC (2010) Mitochondrial fusion is required for mtDNA stability in skeletal muscle and tolerance of mtDNA mutations. Cell 141:280-289. CrossRef Medline

Chui DH, Tanahashi H, Ozawa K, Ikeda S, Checler F, Ueda O, Suzuki H, Araki W, Inoue H, Shirotani K, Takahashi K, Gallyas F, Tabira T (1999) Transgenic mice with Alzheimer presenilin 1 mutations show accelerated neurodegeneration without amyloid plaque formation. Nat Med 5:560564. CrossRef Medline de Brito OM, Scorrano L (2008) Mitofusin 2 tethers endoplasmic reticulum to mitochondria. Nature 456:605-610. CrossRef Medline

Detmer SA, Vande Velde C, Cleveland DW, Chan DC (2008) Hindlimb gait defects due to motor axon loss and reduced distal muscles in a transgenic mouse model of Charcot-Marie-Tooth type 2A. Hum Mol Genet 17:367375. CrossRef Medline

El Fissi N, Rojo M, Aouane A, Karatas E, Poliacikova G, David C, Royet J, Rival T (2018) Mitofusin gain and loss of function drive pathogenesis in Drosophila models of CMT2A neuropathy. EMBO Rep 19:e45241. CrossRef Medline

Feely SM, Laura M, Siskind CE, Sottile S, Davis M, Gibbons VS, Reilly MM, Shy ME (2011) MFN2 mutations cause severe phenotypes in most patients with CMT2A. Neurology 76:1690-1696. CrossRef Medline

Figiel M, Szlachcic WJ, Switonski PM, Gabka A, Krzyzosiak WJ (2012) Mouse models of polyglutamine diseases: review and data table. Part I. Mol Neurobiol 46:393-429. CrossRef Medline

Franco A, Kitsis RN, Fleischer JA, Gavathiotis E, Kornfeld OS, Gong G, Biris N, Benz A, Qvit N, Donnelly SK, Chen Y, Mennerick S, Hodgson L, Mochly-Rosen D, Dorn GW II (2016) Correcting mitochondrial fusion by manipulating mitofusin conformations. Nature 540:74-79. CrossRef Medline

Inoue T, Hoshina N, Nakazawa T, Kiyama Y, Kobayashi S, Abe T, Yamamoto T, Manabe T, Yamamoto T (2014) LMTK3 deficiency causes pronounced locomotor hyperactivity and impairs endocytic trafficking. J Neurosci 34:5927-5937. CrossRef Medline

Ishihara N, Nomura M, Jofuku A, Kato H, Suzuki SO, Masuda K, Otera H, Nakanishi Y, Nonaka I, Goto Y, Taguchi N, Morinaga H, Maeda M, Takayanagi R, Yokota S, Mihara K (2009) Mitochondrial fission factor Drp1 is essential for embryonic development and synapse formation in mice. Nat Cell Biol 11:958-966. CrossRef Medline

Khacho M, Slack RS (2018) Mitochondrial dynamics in the regulation of neurogenesis: from development to the adult brain. Dev Dyn 247:47-53. CrossRef Medline

Lee Y, Dawson VL, Dawson TM (2012) Animal models of Parkinson's disease: vertebrate genetics. Cold Spring Harb Perspect Med 2:a009324. CrossRef Medline

Liu Q, Kang L, Wang L, Zhang L, Xiang W (2016) Mitofusin 2 regulates the oocytes development and quality by modulating meiosis and mitochondrial function. Sci Rep 6:30561. CrossRef Medline

Manczak M, Kandimalla R, Fry D, Sesaki H, Reddy PH (2016) Protective effects of reduced dynamin-related protein 1 against amyloid betainduced mitochondrial dysfunction and synaptic damage in Alzheimer's disease. Hum Mol Genet 25:5148-5166. CrossRef Medline

Mayford M, Bach ME, Huang YY, Wang L, Hawkins RD, Kandel ER (1996) Control of memory formation through regulated expression of a CaMKII transgene. Science 274:1678-1683. CrossRef Medline

McKinney BC, Schneider JS, Schafer GL, Lowing JL, Mohan S, Zhao MX, Heng MY, Albin RL, Seasholtz AF, Akil H, Murphy GG (2008) Decreased locomotor activity in mice expressing tTA under control of the CaMKII alpha promoter. Genes Brain Behav 7:203-213. CrossRef Medline

Mishima E, Inoue C, Saigusa D, Inoue R, Ito K, Suzuki Y, Jinno D, Tsukui Y, Akamatsu Y, Araki M, Araki K, Shimizu R, Shinke H, Suzuki T, Takeuchi Y, Shima H, Akiyama Y, Toyohara T, Suzuki C, Saiki Y, et al. (2014) Conformational change in transfer RNA is an early indicator of acute cellular damage. J Am Soc Nephrol 25:2316-2326. CrossRef Medline

Miyakawa T, Leiter LM, Gerber DJ, Gainetdinov RR, Sotnikova TD, Zeng H, Caron MG, Tonegawa S (2003) Conditional calcineurin knockout mice exhibit multiple abnormal behaviors related to schizophrenia. Proc Natl Acad Sci U S A 100:8987-8992. CrossRef Medline

Nakada K, Inoue K, Ono T, Isobe K, Ogura A, Goto YI, Nonaka I, Hayashi JI (2001) Inter-mitochondrial complementation: mitochondria-specific system preventing mice from expression of disease phenotypes by mutant mtDNA. Nat Med 7:934-940. CrossRef Medline

Nakada K, Sato A, Sone H, Kasahara A, Ikeda K, Kagawa Y, Yonekawa H, Hayashi J (2004) Accumulation of pathogenic $\Delta$ mtDNA induced deafness but not diabetic phenotypes in mito-mice. Biochem Biophys Res Commun 323:175-184. CrossRef Medline

Nordberg A (2004) PET imaging of amyloid in Alzheimer's disease. Lancet Neurol 3:519-527. CrossRef Medline 
Ogasawara E, Nakada K, Hayashi J (2010) Lactic acidemia in the pathogenesis of mice carrying mitochondrial DNA with a deletion. Hum Mol Genet 19:3179-3189. CrossRef Medline

Reddy PH, Reddy TP, Manczak M, Calkins MJ, Shirendeb U, Mao P (2011) Dynamin-related protein 1 and mitochondrial fragmentation in neurodegenerative diseases. Brain Res Rev 67:103-118. CrossRef Medline

Rouzier C, Bannwarth S, Chaussenot A, Chevrollier A, Verschueren A, Bonello-Palot N, Fragaki K, Cano A, Pouget J, Pellissier JF, Procaccio V, Chabrol B, Paquis-Flucklinger V (2012) The MFN2 gene is responsible for mitochondrial DNA instability and optic atrophy "plus" phenotype. Brain 135:23-34. CrossRef Medline

Sasaguri H, Nilsson P, Hashimoto S, Nagata K, Saito T, De Strooper B, Hardy J, Vassar R, Winblad B, Saido TC (2017) APP mouse models for Alzheimer's disease preclinical studies. EMBO J 36:2473-2487. CrossRef Medline

Strickland AV, Rebelo AP, Zhang F, Price J, Bolon B, Silva JP, Wen R, Züchner S (2014) Characterization of the mitofusin 2 R94W mutation in a knock-in mouse model. J Peripher Nerv Syst 19:152-164. CrossRef Medline
Stuppia G, Rizzo F, Riboldi G, Del Bo R, Nizzardo M, Simone C, Comi GP, Bresolin N, Corti S (2015) MFN2-related neuropathies: clinical features, molecular pathogenesis and therapeutic perspectives. J Neurol Sci 356:7-18. CrossRef Medline

van Hall G, Strømstad M, Rasmussen P, Jans O, Zaar M, Gam C, Quistorff B, Secher NH, Nielsen HB (2009) Blood lactate is an important energy source for the human brain. J Cereb Blood Flow Metab 29:1121-1129. CrossRef Medline

Wallace DC (1999) Mitochondrial diseases in man and mouse. Science 283: 1482-1488. CrossRef Medline

Wiederkehr A, Wollheim CB (2012) Mitochondrial signals drive insulin secretion in the pancreatic beta-cell. Mol Cell Endocrinol 353:128-137. CrossRef Medline

Zuchner S, Mersiyanova IV, Muglia M, Bissar-Tadmouri N, Rochelle J, Dadali EL, Zappia M, Nelis E, Patitucci A, Senderek J, Parman Y, Evgrafov O, Jonghe PD, Takahashi Y, Tsuji S, Pericak-Vance MA, Quattrone A, Battaloglu E, Polyakov AV, Timmerman V, et al. (2004) Mutations in the mitochondrial GTPase mitofusin 2 cause charcot-marie-tooth neuropathy type 2A. Nat Genet 36:449-451. CrossRef Medline 